NOTICE: This is the peer reviewed version of the following article: Miguel Martínez-Calvo, José L. Mascareñas (2018). Organometallic catalysis in biological media and living settings.

Coord. Chem. Rev. 359, 57-79 [doi: 10.1016/j.ccr.2018.01.011]

(C2018. This manuscript version is made available under the CC-BY-NC-ND 4.0

license http://creativecommons.org/licenses/by-nc-nd/4.0/ 
Review

\title{
Organometallic catalysis in biological media and living settings
}

\author{
Miguel Martínez-Calvo*, José L. Mascareñas* \\ Centro Singular de Investigación en Química Biolóxica e Materiais Moleculares (CIQUS) and Departamento de Química Orgánica, Universidade de Santiago de Compostela, \\ 15782 Santiago de Compostela, Spain
}

\section{A R T I C L E I N F O}

\section{Article history:}

Received 12 October 2017

Accepted 7 January 2018

Available online $\mathrm{xxxx}$

\section{Keywords:}

Organometallic

Bioorthogonal

Transition metal catalysis

Living cells

Artificial metalloenzymes

\begin{abstract}
A B S T R A C T
Organometallic catalysis has allowed the development of an impressive number of chemical transformations that could not be achieved using classical methodologies. Most of these reactions have been accomplished in organic solvents, and in many cases in the absence of water, and under air-free conditions. The increasing pressure to develop more sustainable transformations has stimulated the discovery of metalcatalyzed reactions that can take place in water. A particularly attractive extension of this chemistry consists of the use of biological relevant aqueous solvents, as this might set the basis to translate catalytic metal complexes to biological settings. While this research field is in its infancy, along the last ten years there have been an increasing number of reports demonstrating the viability of achieving metalpromoted transformations in biologically relevant contexts. In this review, that does not intend to be comprehensive, we summarize the most significant advances in the area, and highlight some of the more important difficulties that must be faced when trying to design biocompatible organometallic catalysts, such us stability, cell uptake, bioorthogonality and toxicity. We will manly focus on transition metal systems which have been showed to keep their activity in complex aqueous buffers and inside living cells.
\end{abstract}

(C) 2018 Published by Elsevier B.V.

\section{Contents}

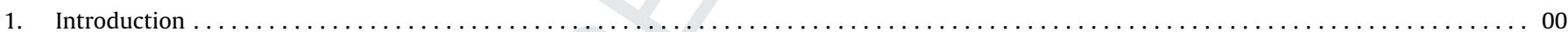

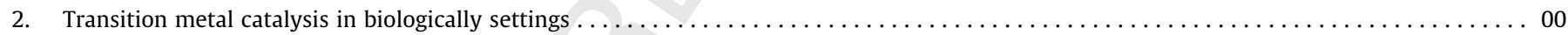

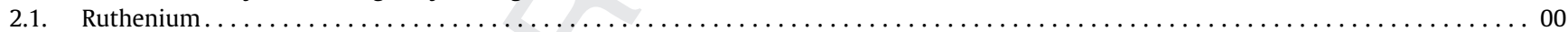

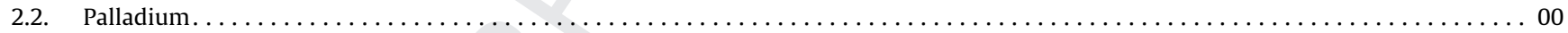

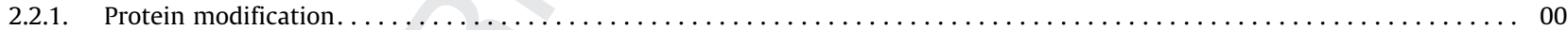

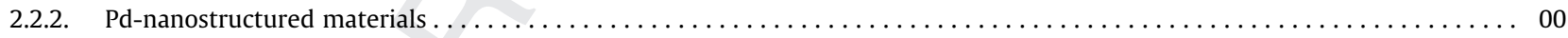

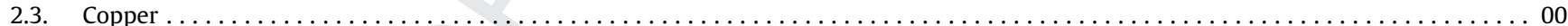

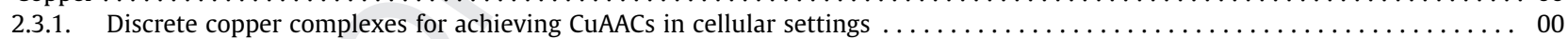

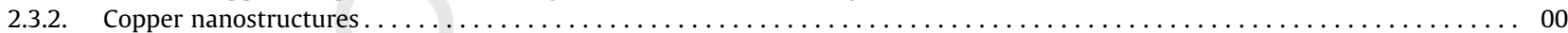

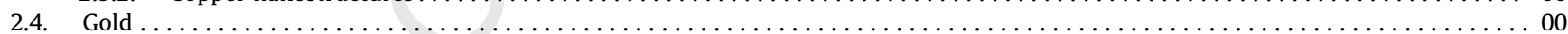

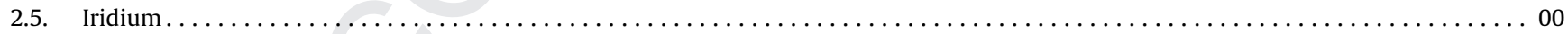

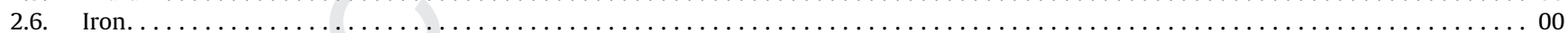

Abbreviations: CuAAC, Copper-Catalyzed Azide-Alkyne Cycloadditions; PhSH, thiophenol; alloc, allylcarbamate group; DAPI, 4',6-diamidine-2'-phenylindole; EtBr, ethidium bromide; TON, turnover number; GSH, glutathione; PBS, phosphate buffered saline; TPP, triphenylphosphonium; IMM, mitochondrial inner membrane; TMRE, tetramethylrhodamine, ethyl ester; ICP-MS, inductively coupled plasma mass spectrometry; RuAtAC, Ruthenium-Catalyzed Azide-Thioalkyne Cycloadditions; GFP, Green Fluorescent Protein; proc, propargylic-carbamate; Neu, neuramic acid; PdNPs, palladium nanoparticles; 5FU, 5-fluoro-1-propargyl-uracil; TFP, ligand tri-2-furylphosphine; HBSS, Hank's Balanced Salt Solution; PEG, polyethylene glycol; PLGA, poly lactic acid-co-glycolic acid; ROS, reactive oxygen species; THPTA, tris-(hydroxypropyltriazo lylmethyl)amine; BTTAA, bis[(tert-butyltriazoyl)methyl]-[(2-carboxymethyltriazoyl)methyl]-amine; TBTA, tris[(1-benzyl-1H-1,2,3-triazol-4-yl)methyl]amine; HPG, homopropargylglycine; TCEP, tris(2-carboxyethyl)phosphine hydrochloride; NaAsc, sodium ascorbate; HEK, human embryonic kidney; FITC, Fluorescein isothiocyanate; OVCAR5, human ovarian cancer cells; CuNPs, copper nanoparticles; E-Cu-NPs, embedded copper nanoparticles; Cu-MONPs, Cu-containing organic nanoparticles; FRET, fluorescence resonance energy transfer; AuNPs, gold nanoparticles; TPP, 5,10,15,20-tetraphenyl-21H,23H-porphine; bPPs, bovine pancreatic polypeptides; ee, enantiomeric excess; PIX, porphyrin IX; TOF, turnover frequency; ATHase, artificial transfer hydrogenase; biot-Sav, biotin-streptavidin; NaPi, sodium phosphate solution.

* Corresponding authors. Fax: +34 881814468.

E-mail addresses: miguel.martinez@usc.es (M. Martínez-Calvo), joseluis.mascarenas@usc.es (J.L. Mascareñas). 


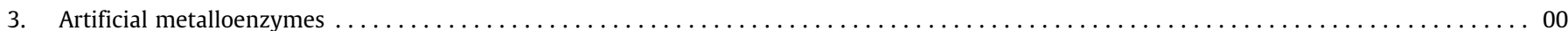

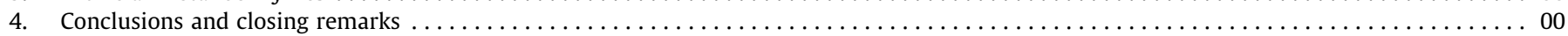

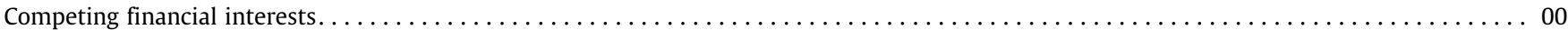

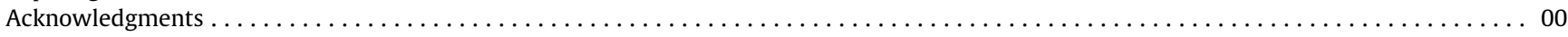

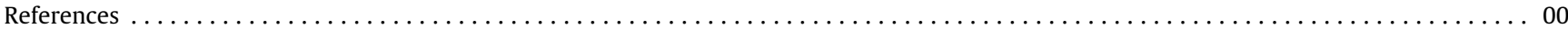

\section{Introduction}

Organometallic catalysis in water is itself a quite new field of research which has been mainly developed within the context of "Green chemistry" [1-6]. In recent years, there have been many reports on metal-catalyzed reactions that can take place in water, including couplings, isomerizations, cyclizations, cycloadditions or hydrolysis processes. Despite this progress, the number of water-compatible organometallic reactions is still very small when compared with transformations achieved in organic solvents $[7,8]$. Thus, one should expect many new contributions in the coming years.

Given that the basic solvent of biological habitats is water, it is not difficult to envision that some of these transformations might be achieved in bio-relevant media. However, the complexity of biological solvents, owing to the presence of a high concentration of biomolecules such as thiols or amines which can poison the metal and kill the catalytic activity, makes extremely challenging to translate metal-catalyzed reactions to such media. Even more difficult is the transfer to living cells, as in this case additional issues such as cell uptake and transport, and especially, side biological activities [9-12], need to be taken into account. In addition, transition metal speciation should be considered, as this could influence the reactivity as well as the toxicity of the metals $[13,14]$; however, studies in this area, in the context of metal-promoted reactions in cell culture, are yet lacking. Anyhow, in recent years there have been many reports on the use of metal complexes in complex aqueous buffers, and even in vivo settings [15-18]. While organometallic catalysis in biological media is yet an emerging discipline, it seems clear that being able to achieve non-natural catalytic transformations of exogenous substrates in bio-settings might unleash a new world of opportunities for biological and medicinal research. This can be of great relevance for instance for the in situ generation of drugs, the amplification of optical signals for the detection of biomarkers, or the metal-promoted modification of biomolecules, among others.

Undoubtedly, one of the key discoveries that has had a more significant impact on the development of biocompatible metalcatalyzed transformations was the report by Sharpless and by Meldal on the famous Copper-Catalyzed Azide-Alkyne Cycloadditions (CuAAC, Scheme 1) [19,20]. This reaction has changed our capability to transform and monitor biomolecules, in some cases even in living atmospheres, in the presence of many other native molecular components. This type of reactions belongs to what Bertozzi coined as Bioorthogonal Chemistry [21,22]. The copper-promoted annulations can be considered as the first metal-catalyzed reactions that could be achieved in complex aqueous media and even in cell culture media for the modification of cell surface sugars [23-25] and proteins [26]. The cytotoxicity of $\mathrm{Cu}(\mathrm{I})$ ions, however, has significantly hindered the application of this reaction in the internal space of living cells.

After these ground-breaking and inspiring developments in bioorthogonal chemistry, other research groups started to investigate the applicability of other metals to this new field of research. Nevertheless, moving to cells is not trivial, as the living cell is a very complex, compartmentalized and dynamic entity, with a very high concentration of biomolecules, including thiols. Despite this, recent data suggest that certain transition metal derivatives can
93

94

95

96

97

98

99

100

101

102

103

104

105

106

107

108

109

110

111

112

113

114

115

116

117

118

119

120

121

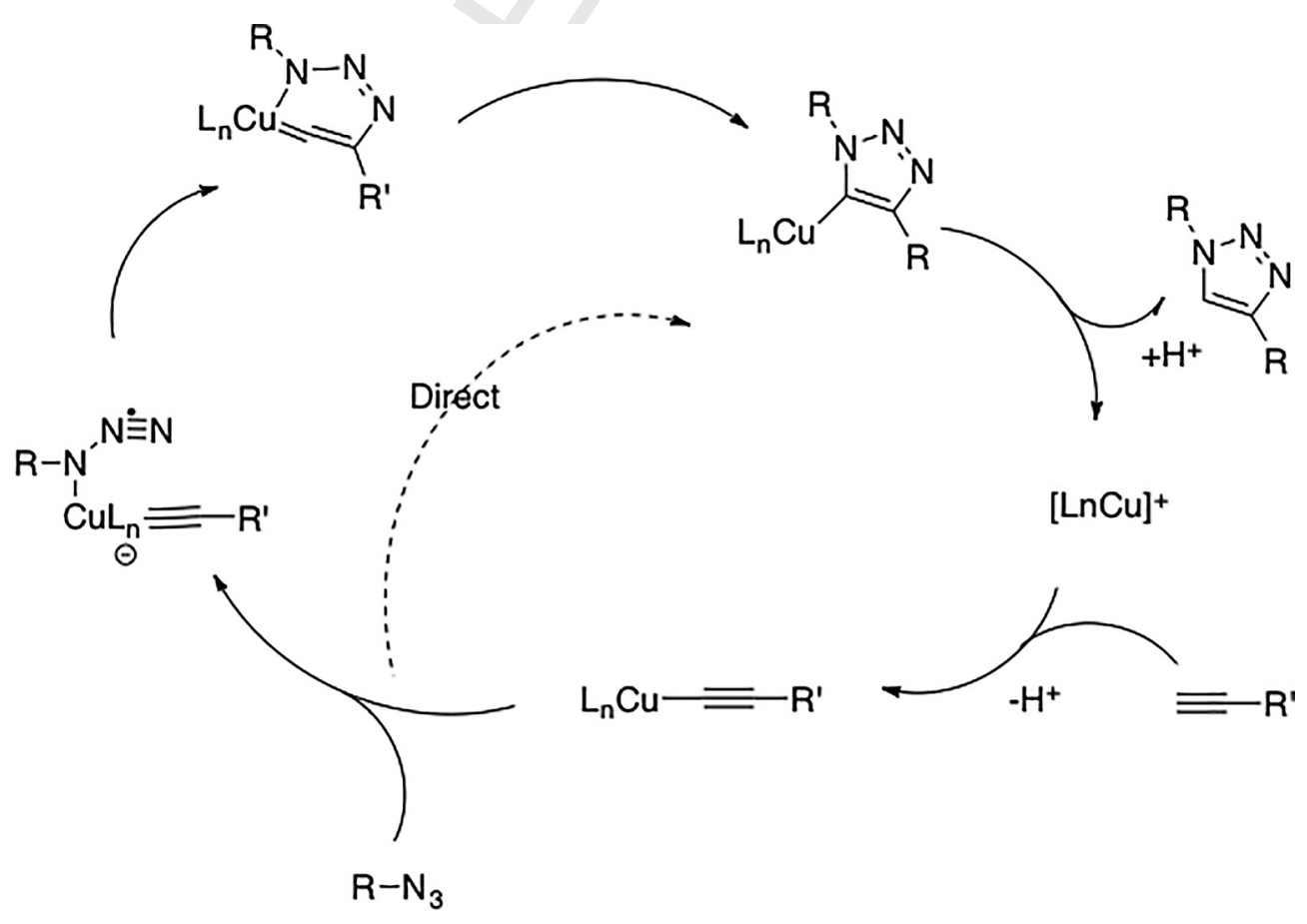

Scheme 1. Initial mechanism proposed by Sharpless for the CuAAC [19]. 
promote intracellular reactions through typical organometallic mechanisms. Here, we have to remark the pioneering work by Streu and Meggers on the development of $\mathrm{Ru}(\mathrm{II})$ catalysts compatible with living cells [27], and by Bradley and co-workers [28] and Chen and co-workers [29] on the development of Pd based systems. In this review, we will summarize some key developments in the field, paying special attention to $\mathrm{Ru}$ and $\mathrm{Pd}$ compounds; but we will also discuss some achievements with other metals. At the end of the review we will also briefly comment on recent developments on the preparation of artificial metalloenzymes.

This field of research is young, but steadily growing, and a number of reviews dealing with transition metal catalysis in biological settings [30-33], bioorthogonal protein modifications [34] and artificial metalloenzymes [35-40], have been already published.

While the above reviews on metal-promoted reactions in biological media are either classified by reaction types, or centered on biopolymer modifications, or on specific metals, we use an organization based on the type of metals. This is particularly illustrative because it gives a comparative idea of the transformative possibilities offered by each of them, and their potential for future applications.

Finally, it is important to note that while in some sentences we might write "metal catalysis", in most of the examples with living systems, turnover has not yet been fully demonstrated.

\section{Transition metal catalysis in biologically settings}

\subsection{Ruthenium}

Organometallic ruthenium complexes have been widely considered in bioinorganic chemistry, especially because of their anticancer potential [41]. Even some of them have shown relevant biological activities owing to their intracellular catalytic activities, for instance by interfering with the balance of GSH and NAD/ $\mathrm{NADH}$, which leads to cell death $[42,43]$. Ruthenium complexes have been widely used in catalytic organometallic chemistry, and therefore translating some of these reactions to biological settings is highly promising. The use of $\mathrm{Ru}(\mathrm{II})$ organometallic complexes as catalytic promoters of exogenous transformations in cellular setting started with a seminal report by Streu and Meggers in 2006, that demonstrated the viability of achieving a metal promoted release allylcarbamate-protecting groups in the interior of HeLa cells (Fig. 1) [27]. For monitoring the reaction, they used as substrate a bis-allylcarbamate caged rhodamine 110 (1) which was virtually non-fluorescent. The uncaging of this molecule gives rise to rhodamine 110 (2) which emits green light upon excitation. The reaction was carried out using $\left[\mathrm{RuCp}^{*}(\mathrm{COD}) \mathrm{Cl}\right](\mathbf{3})$ as catalyst (Fig. 2). They first carried out an in vitro exploration of the best conditions to achieve a Ru-promoted cleavage of the allylcarbamate group (alloc) of a protected $p$-methylaniline, under a variety of aqueous buffers, finding that the reaction is better achieved in the presence of nucleophilic thiols.

They then moved to living HeLa Cells, observing that when the cells were pre-incubated with $\mathbf{1}(100 \mu \mathrm{M})$ for $30 \mathrm{~min}$, washed with PBS buffer solution, and then treated with the ruthenium complex $3(20 \mu \mathrm{M})$ and thiophenol (PhSH) $(500 \mu \mathrm{M})$, there is an increase in green light emission due to the release of $\mathbf{2}$ (Fig. 1). A few years later, the same authors carried out a similar deprotection reaction using another $\mathrm{Ru}(\mathrm{II})$ organometallic precursor $\left[\mathrm{RuCp}^{*}\left(\eta^{6}\right.\right.$-pyrene)] $\mathrm{PF}_{6}$ (4, Fig. 2), that can be activated (detachment of the pyrene ligand) by irradiation with light $(\lambda=330 \mathrm{~nm})$. As in the case of $\mathbf{3}$, the reaction with 4 also needed the presence of $\mathrm{PhSH}$ as additive [44]. The next contribution in this area was achieved by the group of Mascareñas et al., who demonstrated that is possible to use the

a)<smiles>[Mg]</smiles>

1

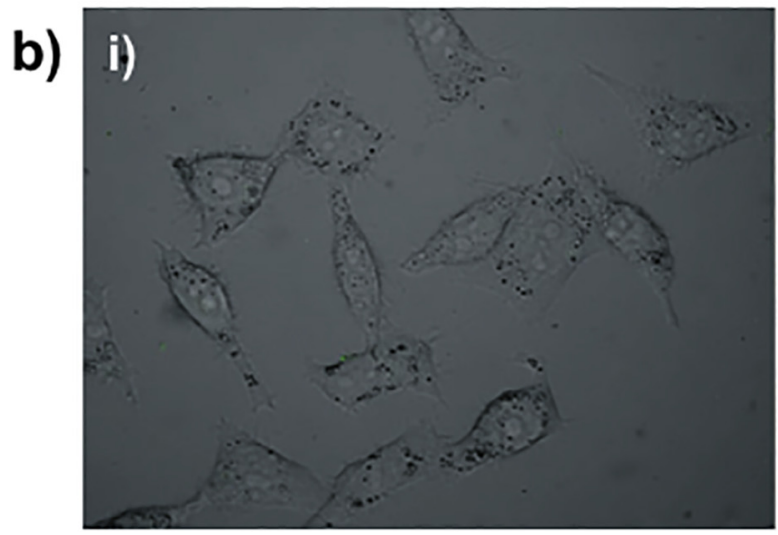

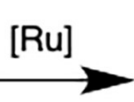
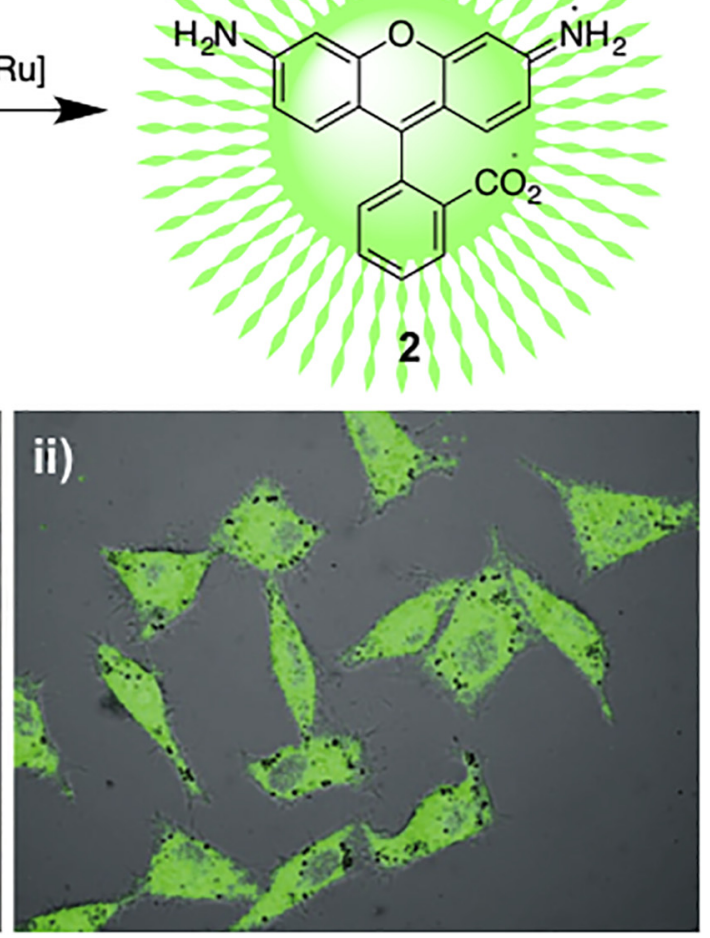

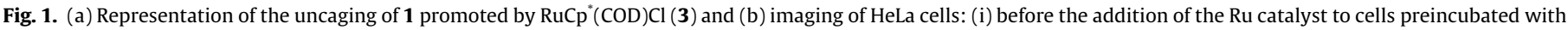
1, and PhSH and (ii) 15 min after the addition of ruthenium complex 3. (b) Adapted by permission [27]. Copyright 2006, Wiley-VCH. 
a)

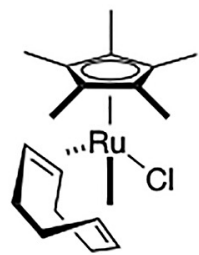

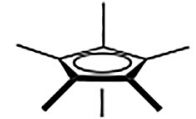

$\mathrm{Ru}$

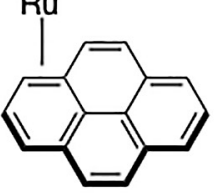

4

c)

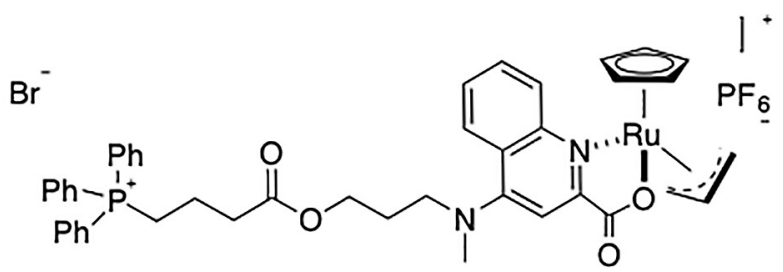

6

3

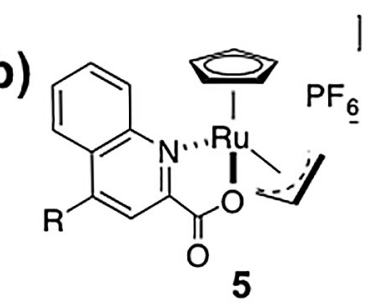

d)

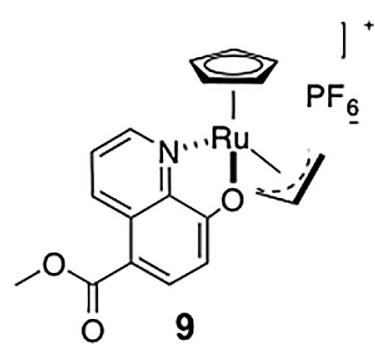

$\mathrm{R}=\mathrm{H}, \mathbf{5 a}$

$\mathrm{R}=\mathrm{OMe}, \mathbf{5 b}$

$\mathrm{R}=\mathrm{NH}_{2}, 5 \mathrm{c}$<smiles>CP(C)(C)(CBr)Cc1ccc2ccc3cccc4ccc1c2c34</smiles>

$\mathrm{Ph}^{\prime} \mathrm{Ph}$

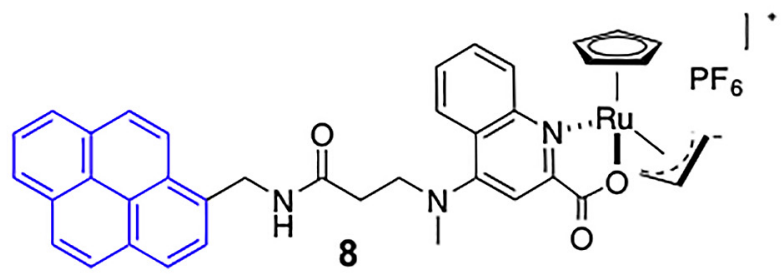

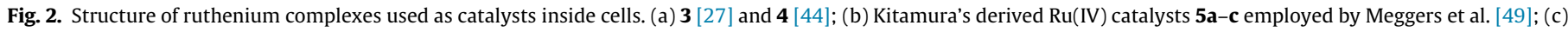

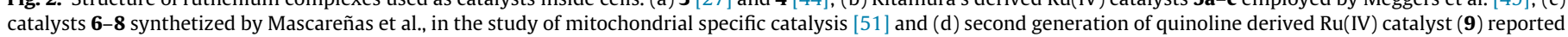
by Meggers et al. [53].

a)<smiles>C=CCOC(=O)NC(=N)c1ccc(-c2cc3ccc(C(=N)NC(=O)OCC=C)cc3[nH]2)cc1</smiles>

10

C)<smiles></smiles>

b)<smiles>[R]NC(=N)c1ccc(NCc2cccc(CNc3ccc(C(=N)N[R])cc3)c2)cc1</smiles>

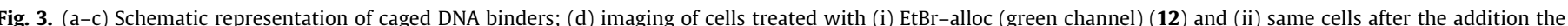

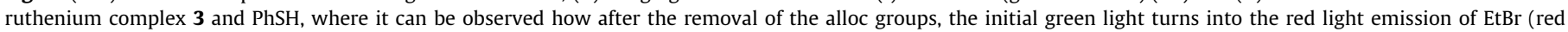
channel) [46].

Ru-promoted reaction to activate DNA binders like 4',6-Diamidine2'-phenylindole (DAPI), Ethidium bromide (EtBr) and bisbenzamidines [45], inside living mammalian cells, by removing inactivating alloc protecting groups from their protected precursors
(DAPI-alloc (10), bisbenzamidines-alloc (11b) and EtBr-alloc (12) (Fig. 3) [46]. The authors carried out several control experiments that were consistent with the reaction taking place inside mammalian cells. These results set the stage for future developments 


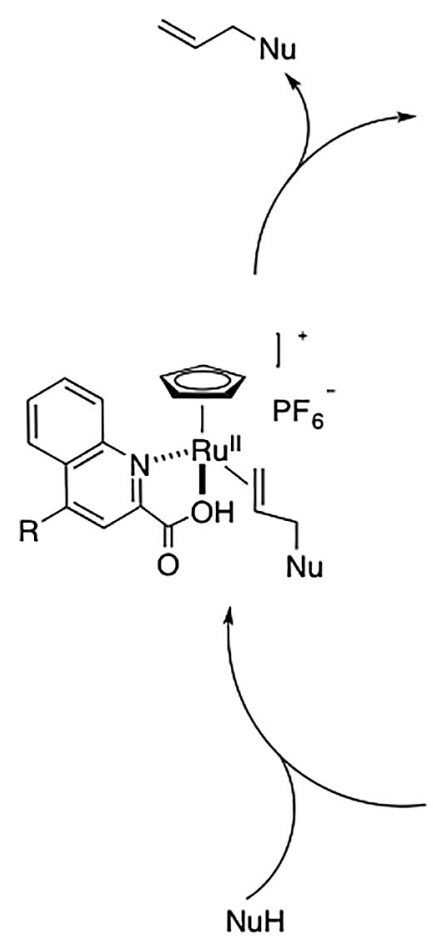

$\mathrm{NuH}$

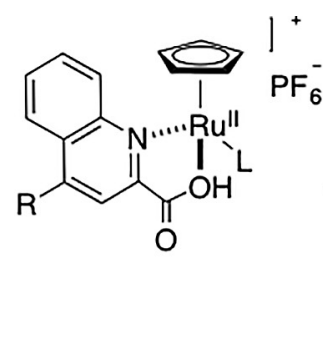<smiles>[Y]CCC(C)CCPNC(=O)OCC=C</smiles><smiles>CCCC</smiles>

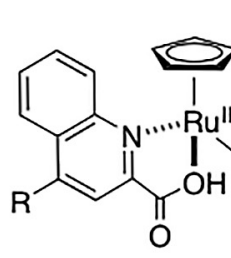

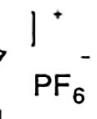

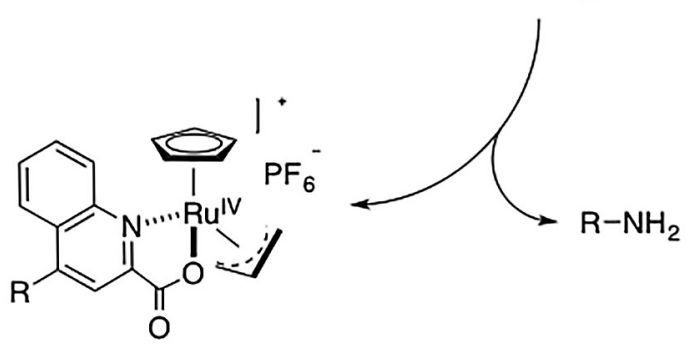

5

on metal-promoted activation of DNA-binding compounds in biological media.

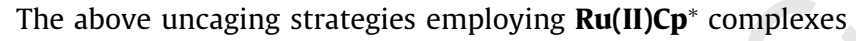
required the use of relatively large amounts of $\mathrm{PhSH}$ as an external nucleophile to ensure turnover, a compound that is toxic to the cells. This problem has been recently solved by Volker and Meggers by using ruthenium(IV) catalysts with quinoline ligands that had been previously described by Kitamura et al., for the catalytic dehydrative allylation of alcohols (Fig. 2b) [47,48]. With these organoruthenium complexes (5, Fig. 2), it was possible to use weaker nucleophiles than PhSH such as glutathione (GSH), which is already present in relatively large amounts inside cells. The authors have proposed the catalytic cycle indicated in the Scheme 2 for the uncaging of alloc protected amines [49].

These catalysts were more active than ruthenium complex $\mathbf{3}$, greatly increasing the turnover number (TON) of the reaction, which could be further modulated by changing the substitution of the position 4 of the quinoline ligand. Thus, the presence of a donor atom at this position increased the catalytic performance (5b, 5c, Fig. 2). Importantly, this type of catalysts can be used in the presence of living mammalian cells without the need to add $\mathrm{PhSH}$ as additive, since glutathione (GSH), which is already present in the cells, acts as nucleophile ( $\mathbf{N u H})$ to close the $\mathrm{Ru}-\pi$-allyl catalytic cycle.

Despite all data suggested that the Ru-catalyzed uncaging is highly effective in the presence of living cells, the intracellular nature of the process was not unambiguously demonstrated.

Noticeable, a paper published by Waymouth and Wender in 2016 using 4T1 cells, suggested that these Ru(IV) complexes are readily washed out with phosphate buffered saline (PBS), and raised doubts on whether the above deallylation reactions is intracellular. In these experiments they describe the removal of an alloc caging group in a luciferase substrate, which allowed for analyzing the cellular reactivity by measuring fluorescent outputs [50].

More recently, the group of Mascareñas et al., exploited the presence of 2-quinolinecarboxylate ligands in the ruthenium complexes for the introduction of different cellular targeting appendages (Fig. 2, complexes 6-8), such as phenyl-phosphonium groups that may accumulate in mitochondria [51]. It is well known that triphenylphosphonium cations (TPP), because of exhibiting both a positive charge delocalized over three phenyl groups and a large hydrophobic surface area, are able to accumulate in the mitochondrial inner membrane (IMM) driven by the membrane potential of this organelle [52]. The authors demonstrated that despite the functional complexity of mitochondria, it was possible to accumulate active ruthenium complexes in this organelle by equipping the ruthenium ligands with suitable arylphophosnium-type of delivery vectors. For the visualization of the metal complexes, one of the phenyl substituents of the TPP was replaced by a methylenepyrene group resulting in a pyrene-phosphonium fluorescent directing vector (complex 7, Fig. 2). Indeed, the presence of the phosphonium group in the structure of the quinoline Ru ligand facilitates the intracellular accumulation and the mitochondrial localization (Fig. 4).

The presence of the pyrene group was observed to have a synergistic effect in the accumulation of the ruthenium complexes in the mitochondria, promoting an increased concentration of $\mathbf{7}$ in this organelle up to 6 -fold compared to the analog 6. Importantly, the ruthenium complex presented a remarkable activity, which was not only tested using standard fluorogenic probes, but also a caged protonophore 1-(allyloxy)-2,4-dinitrobenzene (13) that becomes an active mitochondrial uncoupler (14) only after in situ Ru-promoted removal of the allyl protecting group (Fig. 5). Indeed, using ruthenium complexes that do not accumulate in the mito- 

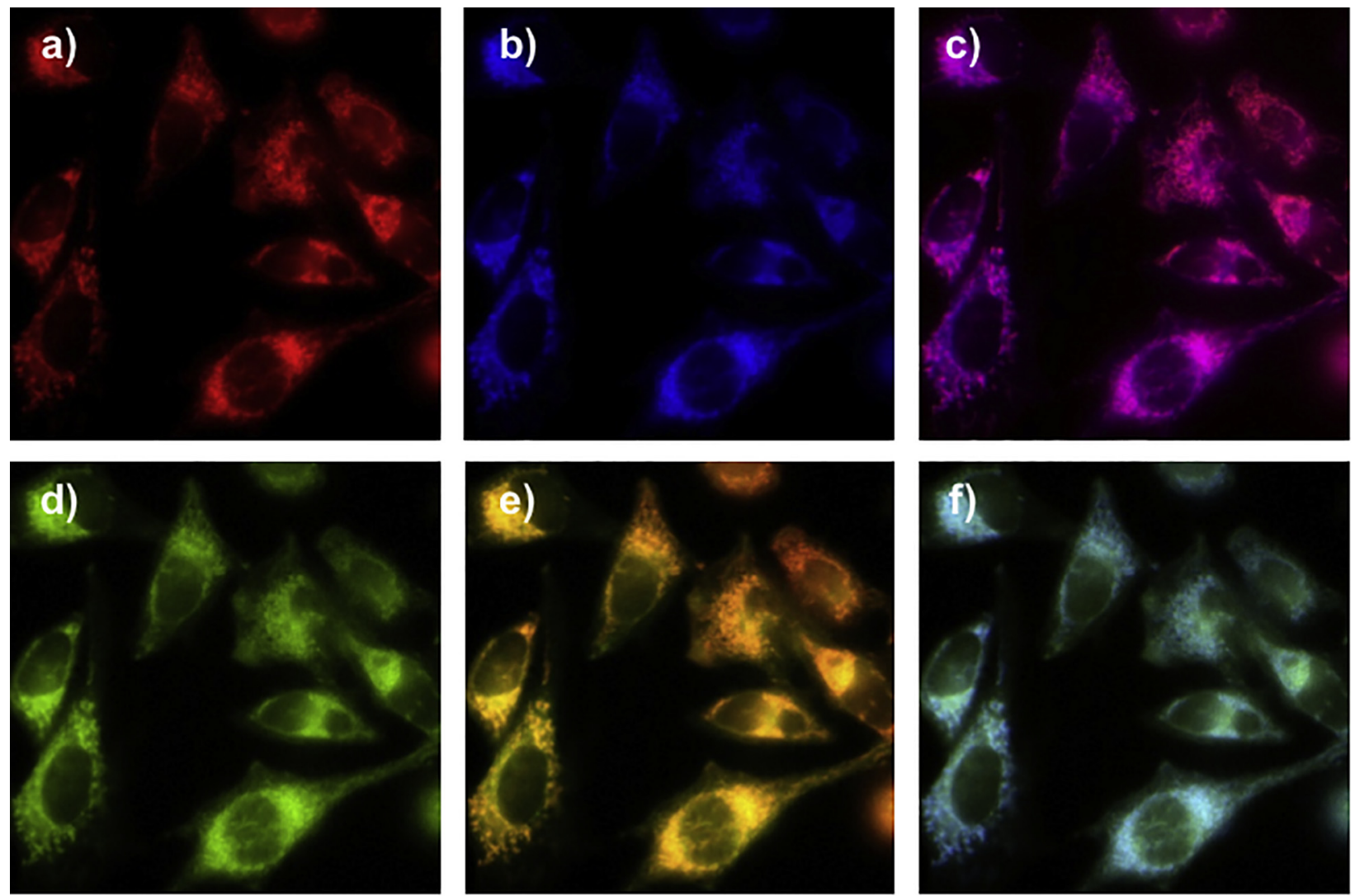

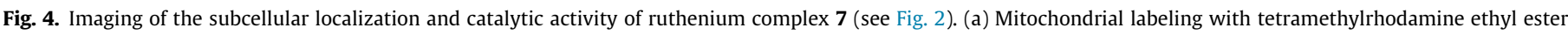

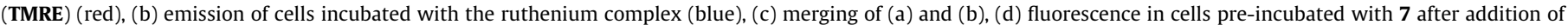
caged rhodamine $\mathbf{1}$, (e) merging of (a) and (d), (f) merging of (b) and (d) [51].

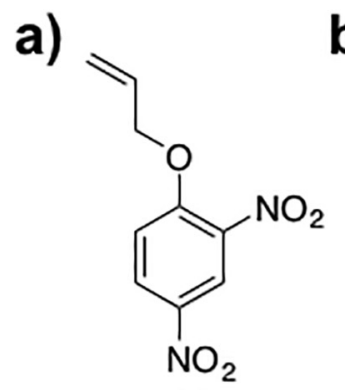

13 b)<smiles>O=[N+]([O-])c1ccc(O)c([N+](=O)[O-])c1</smiles>

14
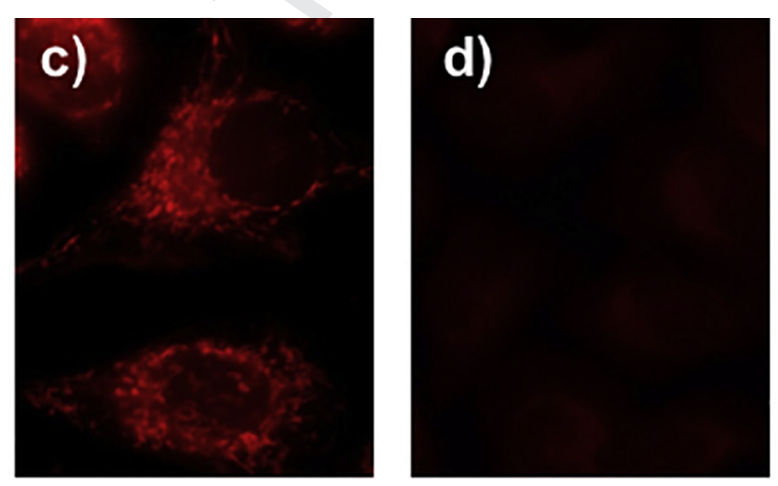

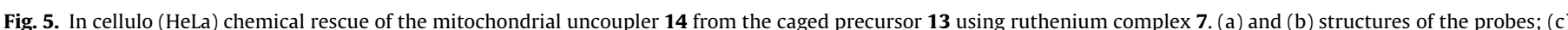

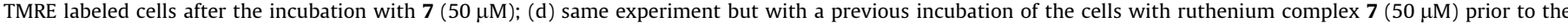

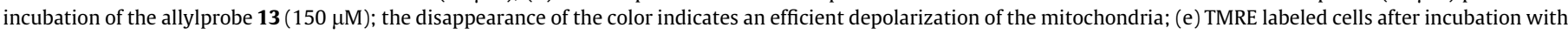
$14(500 \mu \mathrm{M})[51]$.

chondria, the uncaging reaction is much less efficient. This result demonstrates for the first time that having an artificial catalyst localized in a specific cell organelle can bring important biological advantages, and sets the stage for future strategies for selective, target associated drug activations.

In this article [51], the intracellular nature of the reaction was further demonstrated by inductively coupled plasma mass spectrometry (ICP-MS) studies, which confirmed the presence of reasonable amounts of ruthenium in the mitochondria, and by incubating the ruthenium complexes prior to the substrates, to ensure their accumulation inside the cells.
In early 2017, Volker and Meggers reported a new generation of Ru complexes with improved stabilities and excellent catalytic potential under bio-relevant conditions, even in blood serum [53]. This new series of catalysts also possess a quinoline derived ligand, 8-hydroxyquinolinate, in which the introduction of withdrawing groups at the position 5 of the aromatic ring gave rise to an increment in the catalytic activity (complex 9, Fig. 2).

All these data confirm that appropriately designed $\mathrm{Ru}$ complexes are able to achieve highly interesting deallylation reactions in biologically relevant complex aqueous mixtures and even in living cells, in a bioorthogonal manner and without generating major 

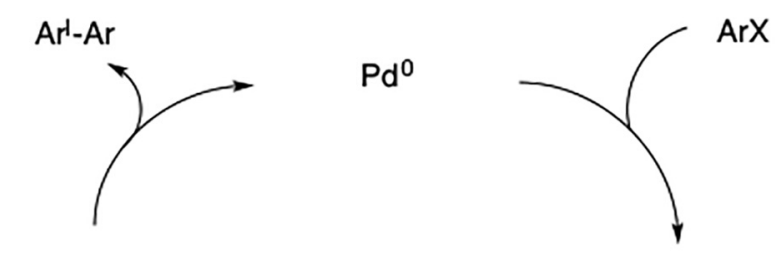

Ar'-Pd(II)-Ar
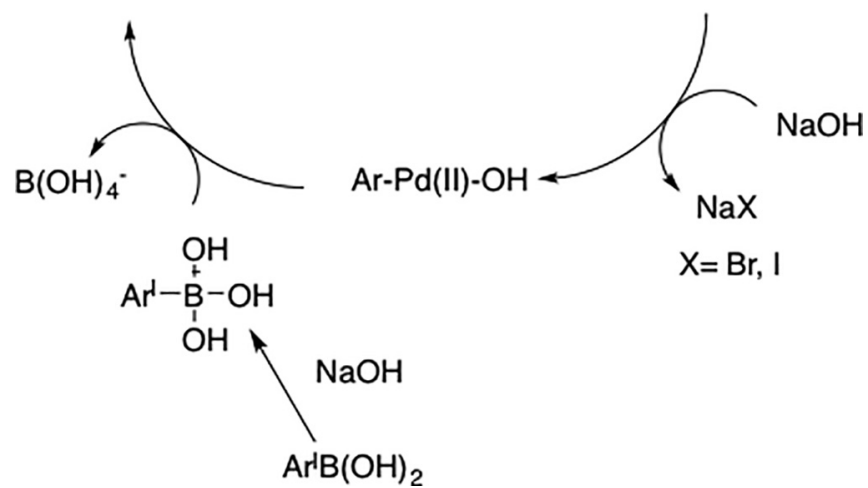

$\mathrm{X}=\mathrm{Br}$, I

Scheme 3. General mechanism for a Suzuki-Miyaura Cross Coupling [60,61].

toxicities. The application of this type of ruthenium complexes for other type of reactions might open new, important opportunities in research at the interface between organometallic catalysis and biological and cellular chemistry. In this context, a recent publication by the group of Mascareñas et al., has demonstrated that complex 3 can promote Ruthenium-Catalyzed Azide-Thioalkyne Cycloadditions (RuAtAC) in water, at room temperature and in the presence of biomolecules (glutathione, aminoacids, peptides) [54]. The reaction is also efficient in phosphate buffered saline (PBS) solution, and in complex biological media such as cell lysates and fetal bovine serum, and even in presence of living bacteria. Importantly, the reaction is mutually compatible with the classical CuAAC, thus providing for tandem bioorthogonal processes [54].

\subsection{Palladium}

The use of palladium in biological environments is very appealing because of the well-demonstrated catalytic power of many palladium complexes [55], even in aqueous environments.

\subsubsection{Protein modification}

Pioneering work by the group of Davies et al. [56,57], demonstrated that using $\mathrm{Pd}(\mathrm{OAc})_{2}$ together with a 2-amino-4,6dihydroxypyrimidine ligands, commonly used in Sonogashira Cross-Couplings in organic solvents [58,59], it is possible to achieve Suzuki-Miyaura Cross-Couplings (Scheme 3) [60,61] on appropriately functionalized proteins, and in biological buffers. In vitro experiments showed that thiols like GSH might have a detrimental influence in the reactions.

They further explored the Suzuki-Miyaura Cross-Coupling reaction for the ${ }^{18} \mathrm{~F}$ labeling of bacterial protein SBL, reactions that required the use of $\mathrm{Pd}(\mathrm{OAc})_{2}$ as palladium source, and some of the ligands L1-L4 indicated in Fig. 6 [62]. The same group was also able to modify the cell-surface of Escherichia coli by using a SuzukiMiyaura Cross Coupling reaction on genetically "tagged" aryl halide-containing porin channels, created through the incorporation of the unnatural amino acid pIPhe into OmpC protein monomers [63]. Despite the undoubtable success of these pioneering findings, these experiments were carried out in vitro or in the cell-surface of $E$. coli, and avoiding the presence of free thiols which seem to interfere with the Cross-Coupling reaction.

It is also remarkable the work of Lin and co-workers in the modification of an overexpressed modified ubiquitin (Ub) protein in $E$. coli which incorporates an homopropargylglycine residue (HPG), using a Sonogashira Cross Coupling reaction (Scheme 4) [64]. They have expanded the application of the Cross-Coupling reaction to the surface of mammalian cells, being able to modify alkynyl-equipped proteins bound to the cellular membrane $[65,66]$. These achievements meant a step forward on the development of metal-promoted chemistry in living cells, however, it was still limited to modify cell-surface-tethered biomolecules.

In 2014, the group of Chen et al., reported the use of discrete Pd (II) catalysts to achieve chemical protein activations in living cells, using a depropargylation or deallylation of caged lysines. In the case of the propargylic (proc) systems, the reaction mechanism is not completely clear, and could proceed via $\mathrm{Pd}^{\mathrm{II} / \mathrm{IV}}$ or $\mathrm{Pd}^{\mathrm{O} / \mathrm{II}}$ cycles (Scheme 5) [29].

The effectivity of the Pd-promoted despropargylation and deallylation reactions was monitored in vitro using the dipropargylcarbamate-rhodamine probe $\mathbf{1 5}$ and bis-allylcarbamate caged rhodamine (1), which become fluorescent (2) after removal of the propargylcarbamate (proc) or allylcarbamate (alloc) protecting groups, respectively (Fig. 7). Among all the catalysts tested in their report, $\mathrm{Pd}_{2}(\text { allyl })_{2} \mathrm{Cl}_{2}$ and $\mathrm{Pd}(\mathrm{dba})_{2}$ resulted the most effective for both types of uncaging in 5/95 DMSO/ $\mathrm{H}_{2} \mathrm{O}$ using an

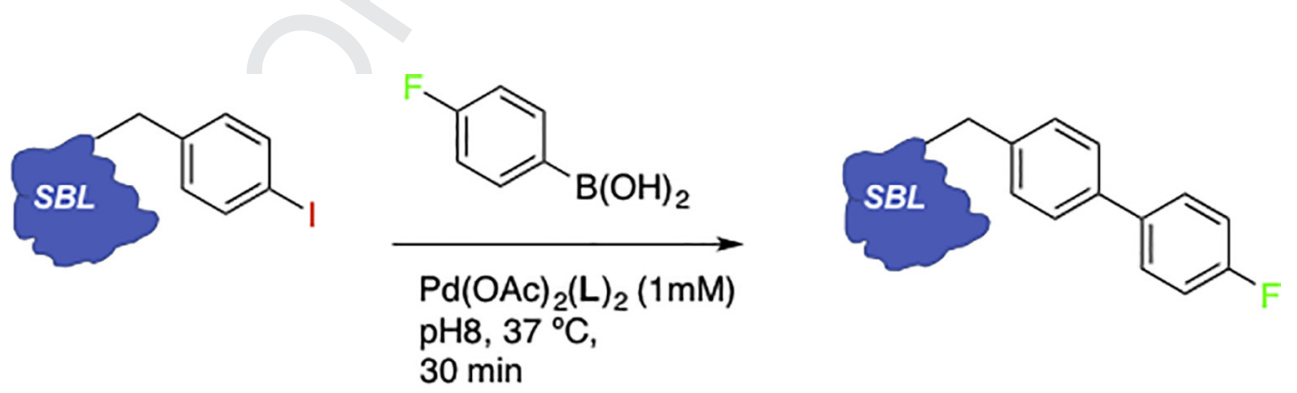<smiles></smiles>

L1<smiles>O=[N+](O)c1cc(O[Na])nc(O[N+]([O-])([O-])[O-])n1</smiles>

L2<smiles>CNC(=N)N</smiles>

L3<smiles>CN(C)C(=N)N(C)C</smiles>

L4

Fig. 6. Representation of the Suzuki-Miyaura Cross-Coupling reaction for the ${ }^{18} \mathrm{~F}$ labeling of $S B L$ protein with $\mathrm{Pd}(\mathrm{OAc})_{2}$ and the ligands $\mathbf{L 1}-\mathbf{L 4}[62]$. 

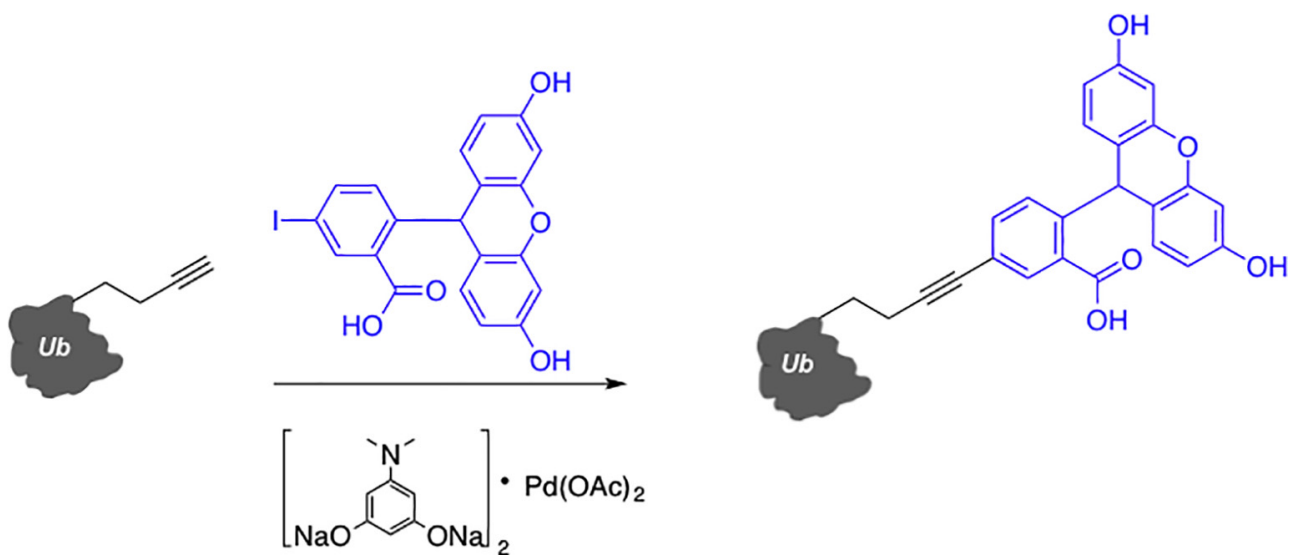

Scheme 4. Sonogashira Cross-Coupling labeling of a HPG-encoded Ub protein in E. coli [64].

a)

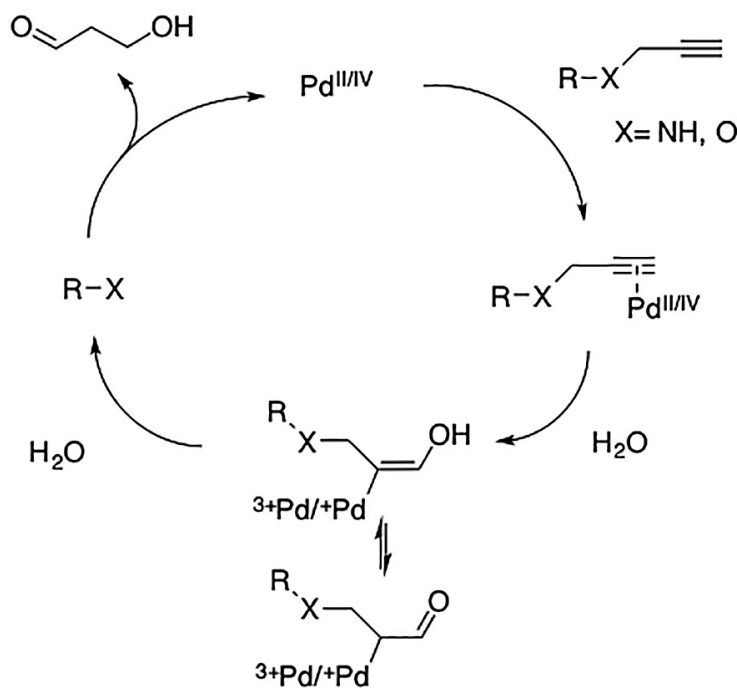

b)
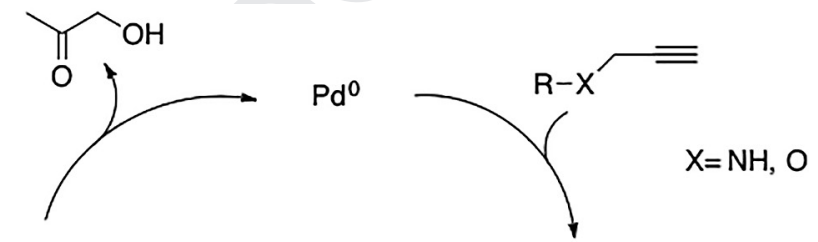

$\mathrm{RXH}$

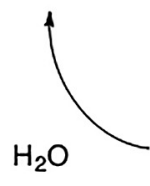

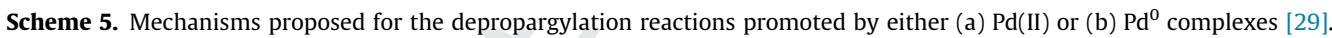

a)<smiles>C#CCOC(=O)Nc1ccc2c(c1)Oc1cc(NC(=O)OCC#C)ccc1C21OC(=O)c2ccccc21</smiles>

15

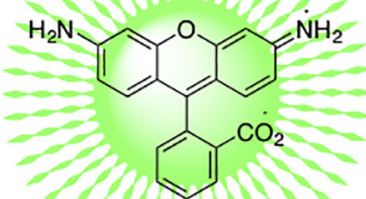

2

b)

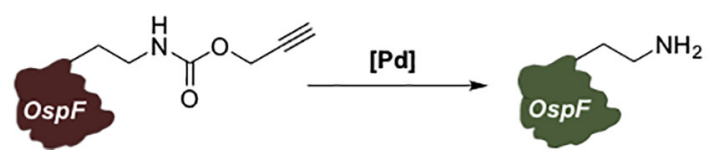

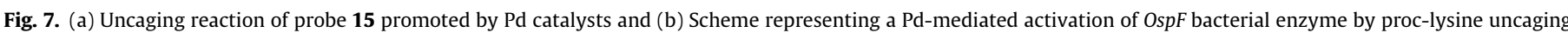
[29].

equimolar ratio $\mathrm{Pd} /$ substrate $(10 \mu \mathrm{M})$ (Fig. 7). Further experiments in vitro using proc-lysine as substrate in PBS buffer, at $37^{\circ} \mathrm{C}$ and $10 \% \mathrm{Pd}$ loading, afforded reaction yields of $84 \%$ with $\mathrm{Pd}(\mathrm{dba})_{2}$ and $82 \%$ with $\mathrm{Pd}_{2}(\text { allyl })_{2} \mathrm{Cl}_{2}$ (Scheme 6).
Neither of these catalysts were able to efficiently uncage alloclysine substrates under the same conditions, 26\% and 22\% yields with $\mathrm{Pd}(\mathrm{dba})_{2}$ and $\mathrm{Pd}_{2}(\text { allyl })_{2} \mathrm{Cl}_{2}$ respectively. The proc-lysine uncaging strategy was used for the chemical rescue of a non- 


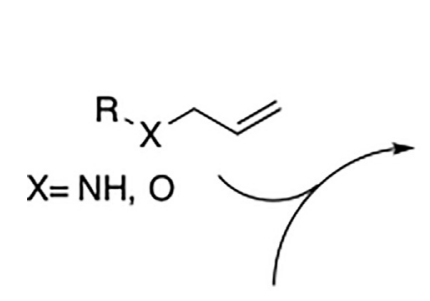

$\widehat{R_{x}}$

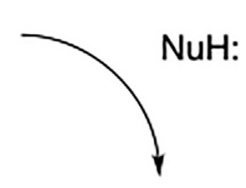

$\mathrm{RXH}$
$\mathrm{Pd}^{0}$

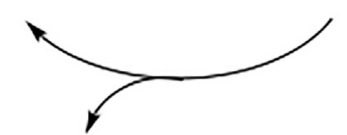

$\sim \mathrm{Nu}$ overexpressed bacterial enzyme phosphothreonine lyase (OspF) within HeLa cells, using $\mathrm{Pd}_{2}(\text { allyl })_{2} \mathrm{Cl}_{2}$ as catalyst (Fig. 7) [29].

The same authors were also able to modify the cell membrane by inducing cellular aggregation processes controlled by a metalpromoted decaging of suitable modified cell-surface proteins [67]. They metabolically engineered the incorporation of neuramic acid (Neu) caged with proc protecting groups (Neu5Proc) into cellsurface glycans. The palladium mediated bioorthogonal uncaging reaction gives rise to the in situ generation of $\mathrm{Neu}$, that is therefore exposed on cell-surface glycans. In this report, the authors keep using the same palladium catalysts as in previous works, although the best results were obtained using palladium nanoparticles
(PdNPs). However, the potential of the strategy is somewhat hampered because these catalysts need to be used immediately after being synthetized [67]. Making use of the same type of Pd complexes, it has also been described the release of intracellular Tyrosine dependent proteins in living cells using genetically encoded proteins containing allene caged tyrosines [68].

The work published by Chen and co-workers represented a very important step forward towards the applicability of Pd catalysts to control the biological activity of designed proteins in living systems. Nevertheless, there are many challenges that remain to be addressed, such as knowing the exact palladium species responsible for the activity. Complexes like $\mathrm{Pd}(\mathrm{dba})_{2}$ and $\mathrm{Pd}_{2}(\text { allyl })_{2} \mathrm{Cl}_{2}$ are known to form $\mathrm{Pd}^{0}$ species, clusters and nanoparticles, depending on the Pd loading [69-72]. Thus, a detailed study of the stability of these complexes and the nature of the real catalysts remains to be performed.

\subsubsection{Pd-nanostructured materials}

Bradley and Unciti-Broceta have pioneered the use of palladium nanostructures to promote chemical transformations in living settings. In their initial work, the authors made use of aminofunctionalised polystyrene microspheres as a support to reduce $\mathrm{Pd}(\mathrm{OAc})_{2}$ to $\mathrm{Pd}^{0}$ nanoparticles (PdNPs, $5 \mathrm{~nm}$ ). These $\mathrm{Pd}^{0}-$ microspheres were demonstrated to be effective for the uncaging of alloc rhodamine $\mathbf{1}$ even in cellular systems. The protocol consists of loading of HeLa cells with the Cy5.5 labeled $\mathrm{Pd}^{0}$-microspheres, following by washing steps, and addition of the fluorogenic rhodamine probe $\mathbf{1}$. Analysis of the result by fluorescence microscopy revealed that the nanostructured $\mathrm{Pd}^{0}$ were able to achieve the desired uncaging.

The catalytic capabilities of these small $\mathrm{Pd}^{0}$ microspheres were also examined in the context of a Suzuki-Miyaura Cross-Coupling<smiles>[C-]S(=O)(=O)Oc1ccc2c(c1)Oc1cc(OCC)ccc1[C@]21OC(=O)c2ccccc21</smiles>

16<smiles>CC1(C)OB(c2ccc(NCCCCP(c3ccccc3)(c3ccccc3)(c3ccccc3)c3ccccc3)cc2)OC1(C)C</smiles>

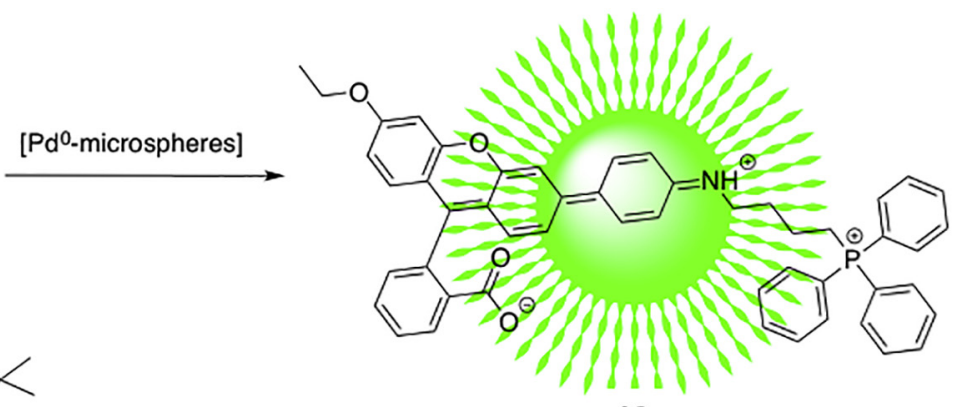

18

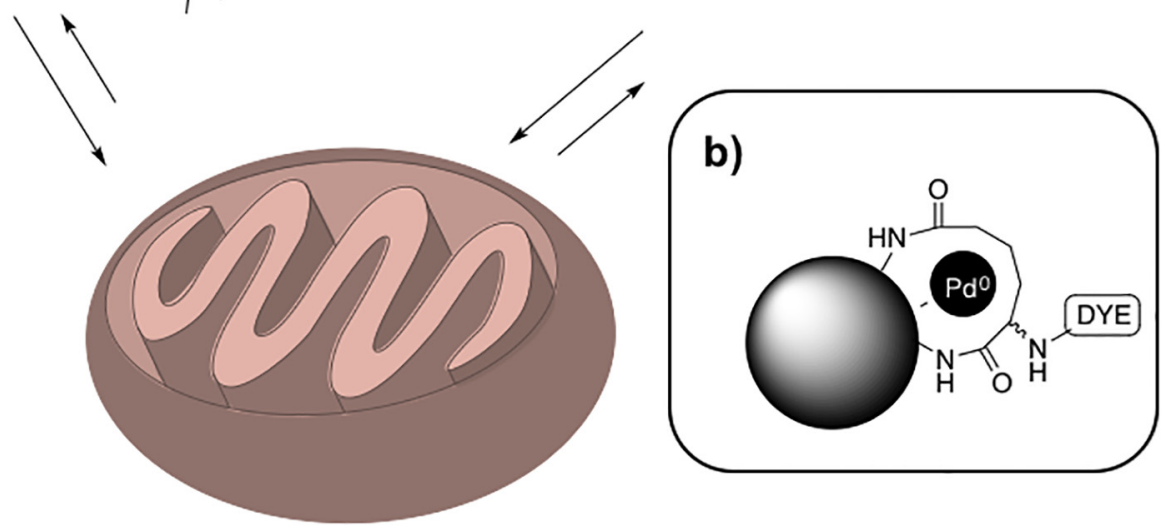

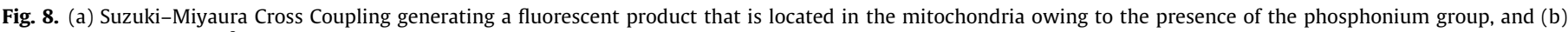
Representation of the $\mathrm{Pd}^{0}$-microspheres used as catalytic systems [28]. 
a)

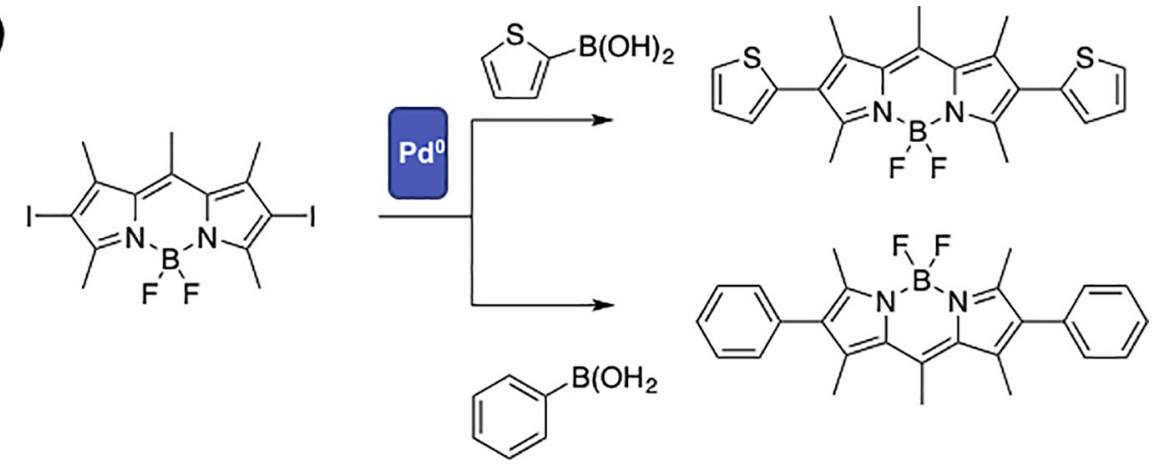

b)

between two exogenous substrates (16 and 17, Fig. 8). The phosphonium moiety was purposely introduced in one of the reactants to achieve the transformation in the mitochondria surroundings [28]. While the result suggests the viability of the coupling reaction, further studies to confirm that this type of bimolecular transformations is taking place in the interior of living cells are certainly necessary. Moreover, the above reactions involved fixation of the cells after the incubation of the $\mathrm{Pd}^{0}$-microspheres and the substrates, which might lead to artefacts or over-interpretations, because, after fixation, the cell membranes are permeable [73]. Therefore, an unambiguous confirmation of the intracellular nature of these reactions would be desirable.

These $\mathrm{Pd}^{0}$-microspheres where further studied for other uncaging processes, such as for an extracellular activation of 5fluorouracil (5FU), from protected allyl, or propargyl derivatives. The palladium-promoted release of this product triggers the apoptosis of the cells [74]. Using a related uncaging strategy promoted by $\mathrm{Pd}^{0}$ microspheres it is also possible to release the anticancer agent vironosat in cellular cultures [75].

Some of these studies were also translated to zebrafish. Inserting the palladium-microspheres in their yolk-sac, the authors were able to observe an increase in the fluorescence after incubation with the fluorogenic probe $\mathbf{1 5}$ [76]. These results should be taken with caution as some alternative studies have shown that the probe might be partially hydrolyzed in the fish [33].

It has also been demonstrated that the $\mathrm{Pd}^{0}$-nanoparticles $(9.2 \pm$ $1.5 \mathrm{~nm}$ ) could also be supported onto a modular polymeric support $(9.9 \times 7.5 \mathrm{~mm})$. These supported $\mathrm{Pd}^{0}$-nanoparticles were capable of inducing depropargylation of fluorogenic probes as $\mathbf{1 5}$, and also promote the formation of bis-aryl BODYPY fluorophores and the anticancer agent $P P-121$ (Fig. 9) by means of Suzuki-Miyaura cross coupling reactions [77].

It has also been shown that it is possible to modify $\mathrm{Pd}^{0}$ microspheres with the cyclic peptide $C R G D f E$, an appendage that allows an specific uptake by brain cancer cells [78]. In this article, Bradley and collaborators also reported the first example of a dual catalytic process in which these $c R G D f E$-functionalized $\mathrm{Pd}^{0}$ microspheres were able to promote the generation of 5FU using an uncaging process, and at the same time promote the synthesis of the anticancer agent $P P-121$ via a Suzuki-Miyaura Cross-Coupling of two benign precursors. Therefore, they are able to generate two different drugs in a dual manner. The authors support the formation of both products in living cells by checking the decrease in cellular viability in the presence of the precursors of both products, and the $\mathrm{Pd}^{0}$ microspheres, whereas in the cases where one of the components is missing, the cell viability was not affected.

In their more recent publication about bioorthogonal reactions promoted by palladium catalysts, Bradley et al., presented two homogeneous tagged carbene-based palladium(II) catalysts conjugated to a cell-penetrating peptide [79]. These catalysts promoted the deprotection of the rhodamine probe $\mathbf{1 5}$ inside PC-3 cells. However, the use of fixed cells advises to be cautious in the interpretation of the results.

Overall, the work by Unciti-Broceta and co-workers have nicely demonstrated the applicability of $\mathrm{Pd}^{0}$ containing microspheres for the promotion of transformations in biological settings. In several of the reports, the large size of the beads suggest that the reactions are indeed taking place in the extracellular matrix.

Other examples on the applicability of palladium catalysts for depropargylation reactions in living settings have been recently reported by Weissleder and co-workers [80]. The authors made a meticulous analysis of the performance of discrete Pd catalysts in vitro under biologically relevant conditions, for the uncaging of proc protected rhodamine $\mathbf{1 5}$ and the alloc derivative $\mathbf{1}$. Removal of propargylic protecting group (proc) was 37\% less efficient than the cleavage of the alloc group. They also identified that electron deficient ligands like tri-2-furylphosphine (TFP) are particularly effective to generate reactive $\mathrm{Pd}^{0}$ species under biological compatible conditions, as TFP readily dissociates from the coordinating sphere of the metal. The authors demonstrated that $\mathrm{PdCl}_{2}(\mathrm{TFP})_{2}$ (19, Fig. 10) is reasonably efficient after $12 \mathrm{~h}$ of pre-incubation in Hank's Balanced Salt Solution (HBSS), however, they observed that 

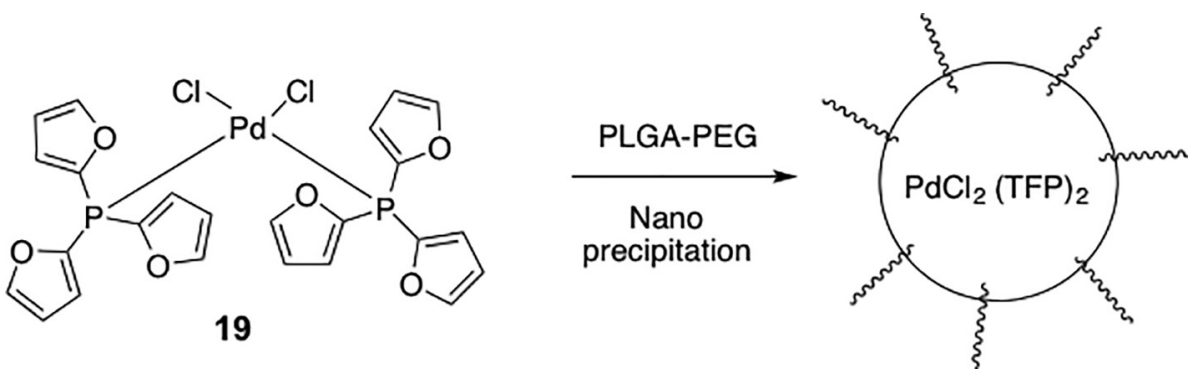

Fig. 10. Schematic representation of the formation of nanostructures from pre-catalyst 19 and PLGA-PEG [80].

TFP and $\mathrm{Cl}^{-}$ligands suffer dynamic ligand exchange processes in biological complex media. Thus, in order to improve catalyst stability and delivery, they encapsulated the precatalyst 19 in a polymeric nanoformulation based on polylactic acid-co-glycolic acid (PLGA) and polyethylene glycol-poly lactic acid-co-glycolic acid (PLGA-PEG). After nanoprecipitation, the resulting nanoparticles resulted quite effective in the above deprotection reactions, and were even tested in vivo using mice as animal model, with promising results [80].

Finally, it is worth to comment that there have been also some reports on the use of fluorogenic probes for the detection of palladium in cellular contexts, albeit the focus of these studies is not in the catalytic activity [81-84].

Overall, we can state that palladium is a powerful metal to promote bioorthogonal catalytic transformations in biological and cellular contexts. In many cases the metal has been used in a nanostructured form, which seems to lead to better results. Caution must be used on concluding that the reactions are taking place inside the cells, particularly when using fixation techniques $[28,74,79]$. The types of reaction so far studied have been essentially restricted to the uncaging of allyl or propargyl protected probes, albeit some isolated examples of Suzuki type of couplings have been also claimed. Considering the enormous potential of palladium complexes in organometallic catalysis, in the near future we should see further biological applications of palladium for promoting other type of reactions in biological contexts. The current knowledge on cell uptake, complex stability and structure/toxicity properties of palladium complexes is yet very limited, and therefore further studies on these matters are clearly needed.

\subsection{Copper}

The paradigm of bioorthogonal reactions that can be achieved in aqueous media is the Copper catalyzed Azide-Alkyne Cycloaddition (CuAAC, Scheme 1), discovered by the groups of Sharpless and Fokin, and Meldal, in 2002 [19,20].

The reaction, typically promoted by a $\mathrm{Cu}(\mathrm{II})$ source, copper ligands, and ascorbate as reductant, presents very good reaction kinetics, high selectivity, and excellent bioorthogonality, and has been extensively used in chemical and cell biology. In comparison with other metal-catalyzed biorthogonal transformations, is the one leading to higher reaction rates.

However most of the "in cellulo" applications have been limited to the modification of cell surface proteins and glycans, and mainly in bacteria. Its use inside livings cells has been precluded in part by the well-known toxicity of copper and ascorbate, which can generate reactive oxygen species (ROS) [85]. The employment of watersoluble tris(triazole) ligands such as tris-(hydroxypropyltriazolyl methyl)amine (THPTA), bis[(tert-butyltriazoyl)methyl]-[(2-carbox ymethyltriazoyl)methyl]-amine (BTTAA), or tris[(1-benzyl-1H-1,2, 3-triazol-4-yl)methyl]amine (TBTA) for $\mathrm{Cu}(\mathrm{I}$ ) (Fig. 11) both accelerate the cycloaddition and decrease the redox side reactivity [86-88].<smiles>CC(C)(C)n1cc(CN(Cc2cn(CC(=O)O)nn2)Cc2cn(C(C)(C)C)nn2)nn1</smiles>

BTTAA

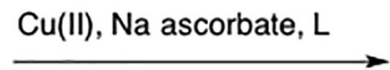<smiles>[R]Cc1cn(C[R])nn1</smiles><smiles>c1ccc(Cn2cc(CN(Cc3cn(Cc4ccccc4)nn3)Cc3cn(Cc4ccccc4)nn3)nn2)cc1</smiles>

THPTA

Fig. 11. General representation of a CuAAC reaction and some stabilizing ligands for $\mathrm{Cu}(\mathrm{I})$. 


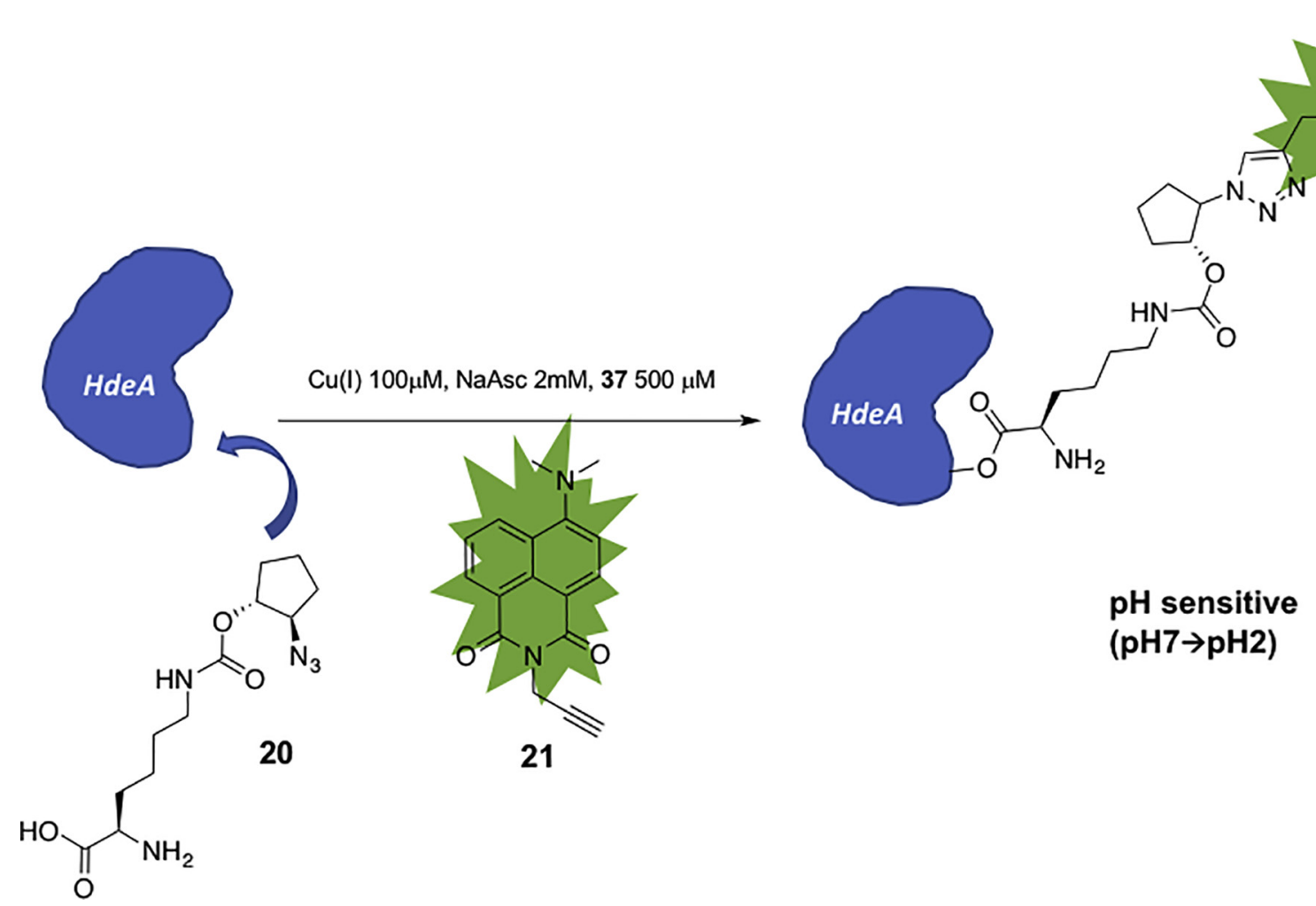

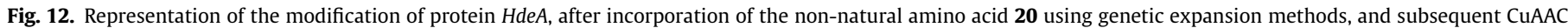
reaction with a $\mathrm{pH}$ sensitive, alkyne-equipped fluorophore [92].

\subsubsection{Discrete copper complexes for achieving CuAACs in cellular settings}

The CuAAC has been very scarcely used inside living cells, probably because obtaining good reactivity requires relatively large amounts of copper, which can be cytotoxic. The pioneering studies on the use of the CuAAC in biological compatible settings were carried out by Link and Tirrell in 2003 [89]. In this work, the authors describe the labeling of cell surface proteins of E. coli, using $\mathrm{CuSO}_{4}$ as copper source and Tris(2-carboxyethyl)phosphine hydrochloride (TCEP) as reducing agent. Later on, they reported an increase in the labeling efficiency by changing the $\mathrm{Cu}$ catalyst to $\mathrm{CuBr}$ [90]. In 2006, they carried out experiments in mammalian cells that included the metabolic incorporation of HPG and a subsequent CuAAC reaction of the resulting proteins with fluorogenic azides. In these experiments, $\mathrm{CuSO}_{4}$ was used as $\mathrm{Cu}$ source, TCEP as reducing agent and cells were fixed before the CuAAC reaction [91].

The group of Chen has used the CuAAC reaction for the modification of a periplasmic pH-responsive acid-chaperone HdeA in E. coli [92]. Therefore, they were able to modify HdeA with the incorporation of ( $N^{\varepsilon}(((1 \mathrm{R}, 2 \mathrm{R})-2$-azidocyclopentyloxy)carbonyl)-1-l ysine) (20), and the resulting proteins can be engaged in a CuAAC coupling with a naphthalimide dye (4-N,N-dimethylamino-1,8-na phthalimide, 21) (Fig. 12). For these experiments the use 1:5 ratios of $\mathrm{CuSO}_{4}$ :BTTAA, and sodium ascorbate (NaAsc) as reducing agent. These experiments were reproducible in BHK-21 mammalian cells expressing the HdeA protein on the cell surface. With this technique, it was possible to explore the extracellular $\mathrm{pH}$ of bacterial or mammalian cells under stressful conditions or during pathogenesis, in a non-invasive fashion.

Later on, the same group demonstrated that it is possible to retarget an azide containing periplasmic protein $H d e A$ to the bacterial cytosol (Cyto-HdeA) of E. coli and that it can be engaged in a CuAAC reaction [93].

The group of Ting pioneered a powerful alternative to the classical CuAAC that has allowed for higher reaction rates and reduced side toxicity. The strategy is based on the use of azides containing pyridine groups to favor the interaction of the azide with the copper complex, and therefore decrease the entropic barrier of the intermolecular annulation. Therefore, using picolyl azides instead of conventional non-chelating azides, they achieved efficient annu-

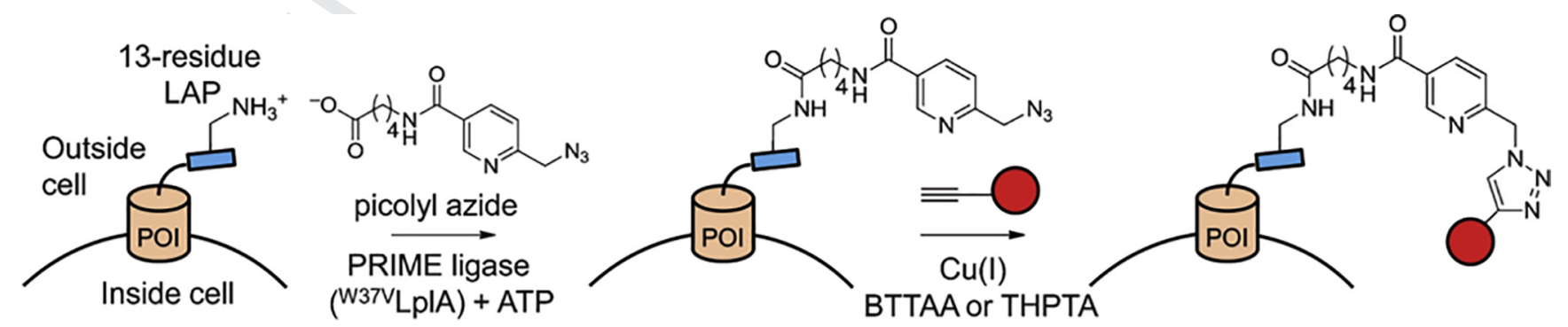

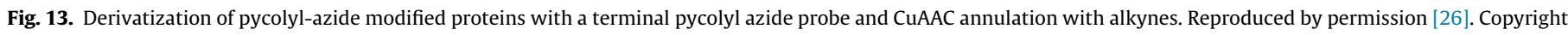
2012, Wiley-VCH. 
<smiles>CCn1cc(CN(CCC[14CH3])Cc2cn(C(C)(C)C)nn2)nn1</smiles>

22

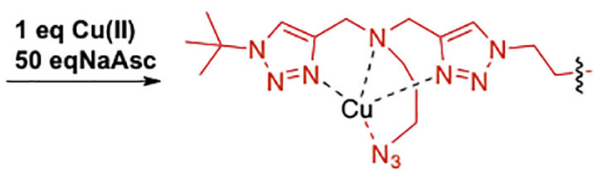

23
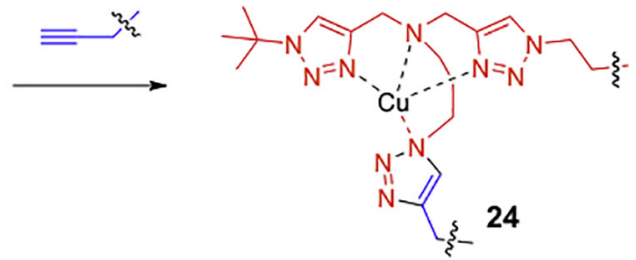

Fig. 14. Chelating azides (22) used by Taran and coworkers to form N3-Cu complexes (23) to promote the CuAAC [94].

a)

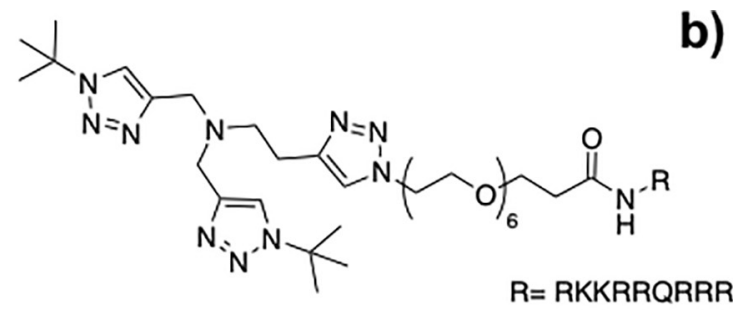

b)<smiles>CC(C)C1SCC2NC(=O)NC21</smiles>

biot- $\mathrm{N}_{3}$

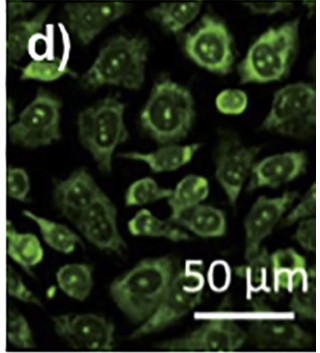

iii)

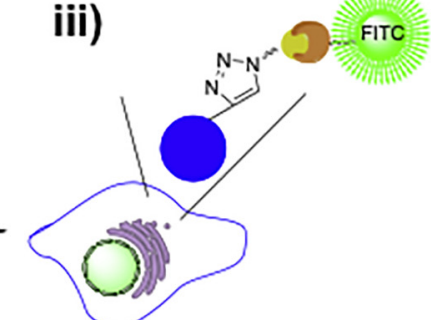

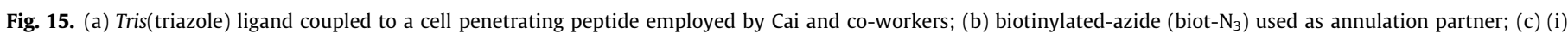

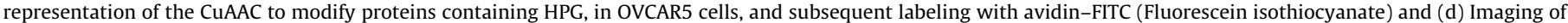
cells after CuAAC reaction, fixation and interaction with Avidin-FITC (green channel) [95].

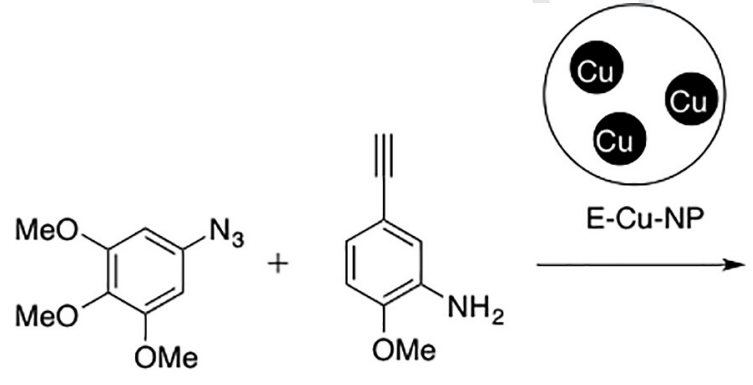

25 ii)

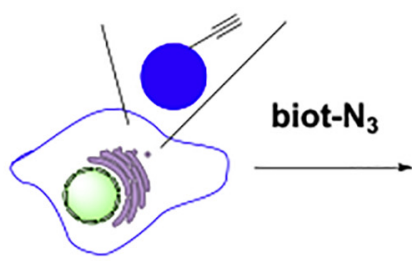

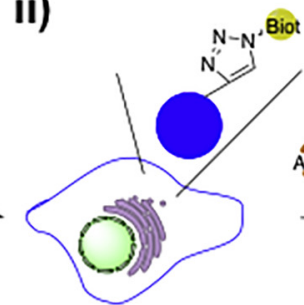

lations with modified proteins on the surface mammalian living human embryonic kidney (HEK) cells. The pycolyl azides can also be incorporated into membrane proteins using enzymatic processes, and then annulated with tagged alkynes using a chelation-assisted CuAAC (Fig. 13) [26].

Inspired by this work, the group of Taran and co-workers, designed alternative azides bearing copper-chelating bis(triazole) moieties (22) which allow the formation of azide copper complexes (23) (Fig. 14) that react almost instantaneously with alkynes under diluted conditions and in complex media [94]. The technology allowed to achieve a CuAAC even inside HUH-7 cells. The authors used cell fixation techniques after the CuAAC reaction in preparations for co-localization studies.

Recently, Cai and co-workers demonstrated that linking copper tris(triazole) ligands to cell penetrating peptides favors the cell internalization and also the intracellular reactivity (Fig. 15) [95]. Using these ligands, they demonstrated the viability of achieving CuAAC reactions to modify cellular proteins incorporating HPG (Fig. 15c). However, the efficiency of the reaction is modest, particularly in the cytoplasm, in part because of the presence of millimolar concentration of GSH, which is known to inhibit the CuAAC. 

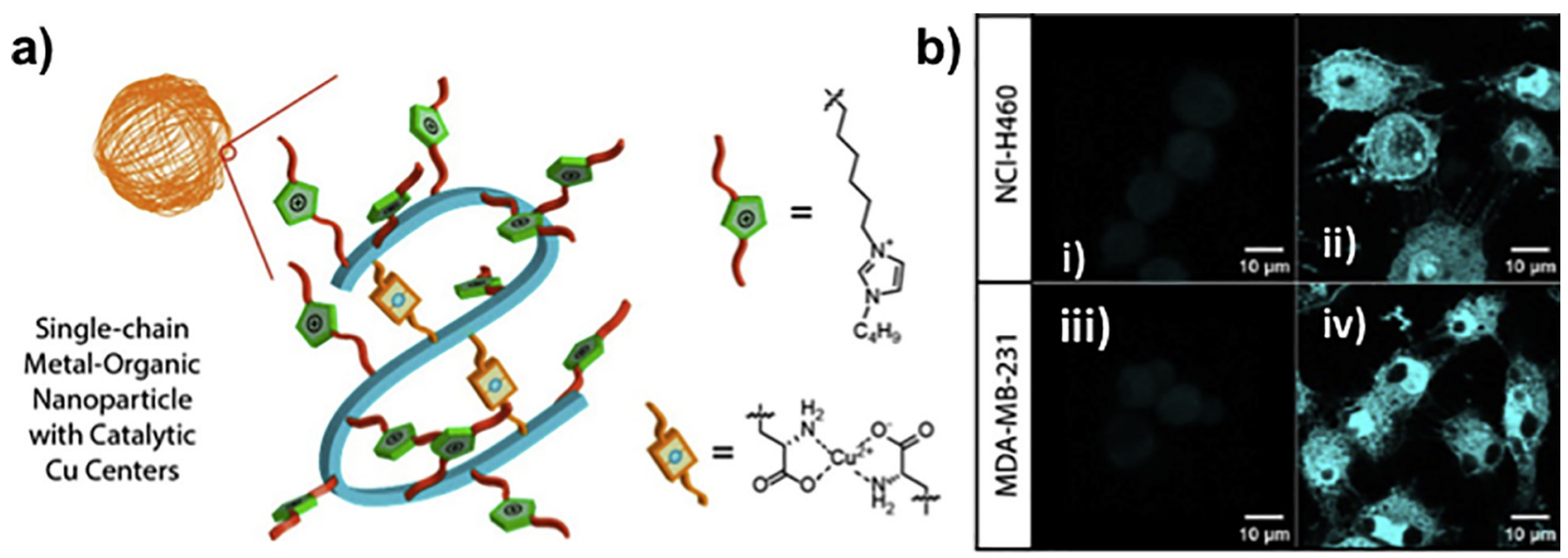

c)<smiles>Nc1cc2ccc(O)cc2oc1=O</smiles><smiles>C#Cc1ccc(OC)cc1</smiles>

Cu-MCNID

NaAsc

\subsubsection{Copper nanostructures}

A couple of recent reports highlight the viability of running CuAAC of exogenous substrates in cellular settings using copper nanostructures. Bradley et al., were able to construct copper nanoparticles (CuNPs, $51.2 \pm 4.2 \mathrm{~nm}$ ) embedded within a polymeric support, in a similar way to that previously used by the group for assembling palladium microspheres (E-Cu-NP; $160 \pm 1$ $0 \mu \mathrm{m}$, Cu content $0.34 \pm 0.02 \mu \mathrm{mol} \mathrm{Cu} / \mathrm{mg}$ resin). The authors demonstrated that these supported $\mathbf{E}-\mathbf{C u}-\mathbf{N P s}$ promoted the reaction of a pro-fluorophore (azide-coumarin) with a small molecule alkyne in the presence of living cells [96]. They also reported the CuAAC of two inert components ( 25 and 26 ) to make a triazole cytotoxic anticancer agent derived from Combretastatin (27) (Scheme 7). Importantly, the reaction takes place in the extracellular medium. They also report the in vivo implantation of the nanostructures in a zebrafish model and the generation of an active fluorophore by means of the designed CuAAC.

Zimmerman et al. have recently demonstrated that $\mathrm{Cu}$ containing organic nanoparticles (Cu-MONPs) are able to catalyze the CuAAC reaction with high efficiency and turnover, not only in water, but also in intracellular settings, both in bacteria and mammalian cells [97]. The $\mathbf{C u - M O N P s}$ were prepared using a $\mathrm{Cu}(\mathrm{II})-$ mediated intramolecular cross-linking of aspartate-containing polyolefins in water. The authors demonstrated the efficiency of the reaction using as fluorogenic probe a 3-azido-7hydroxycoumarin which upon reaction with p-ethynylanisole leads to a highly fluorescent product (Fig. 16). The strategy made possible to selectively synthesize inside cells compounds that otherwise might be difficult to deliver.

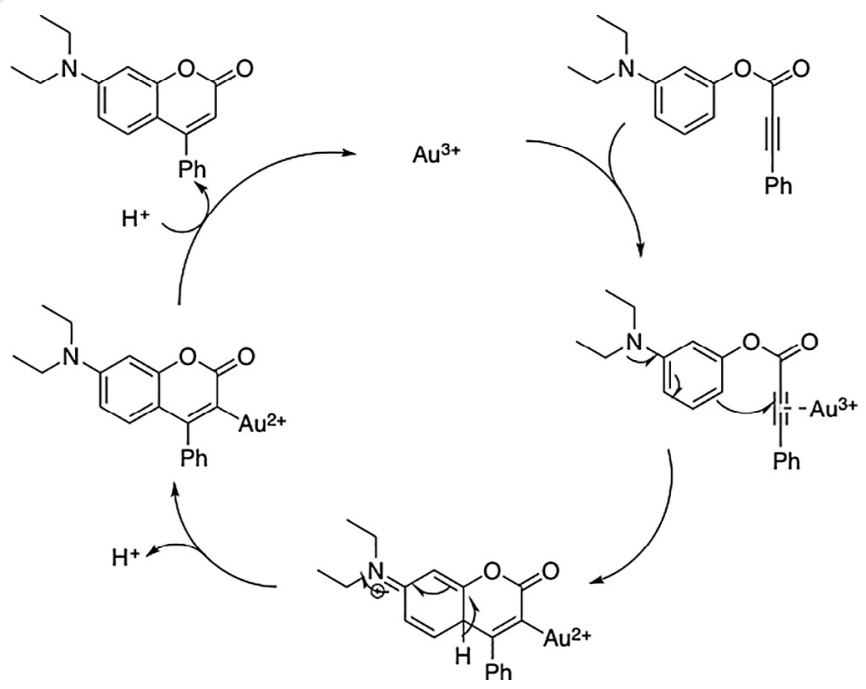

Scheme 8. Proposed catalytic mechanism of gold(III) mediated hydroarylation to give fluorescent coumarins [109].

Overall, we can conclude that the CuAAC can be successfully applied for tagging genetically/modified proteins on the cell surface, particularly in bacteria. Achieving the reaction inside living cells is much more difficult, especially when using two small molecules reacting partners. The use of chelating azides seems to be the more appropriate tactic to achieve reasonable rates and avoid toxicities, albeit the requirement of copper chelation compromises the 
a)

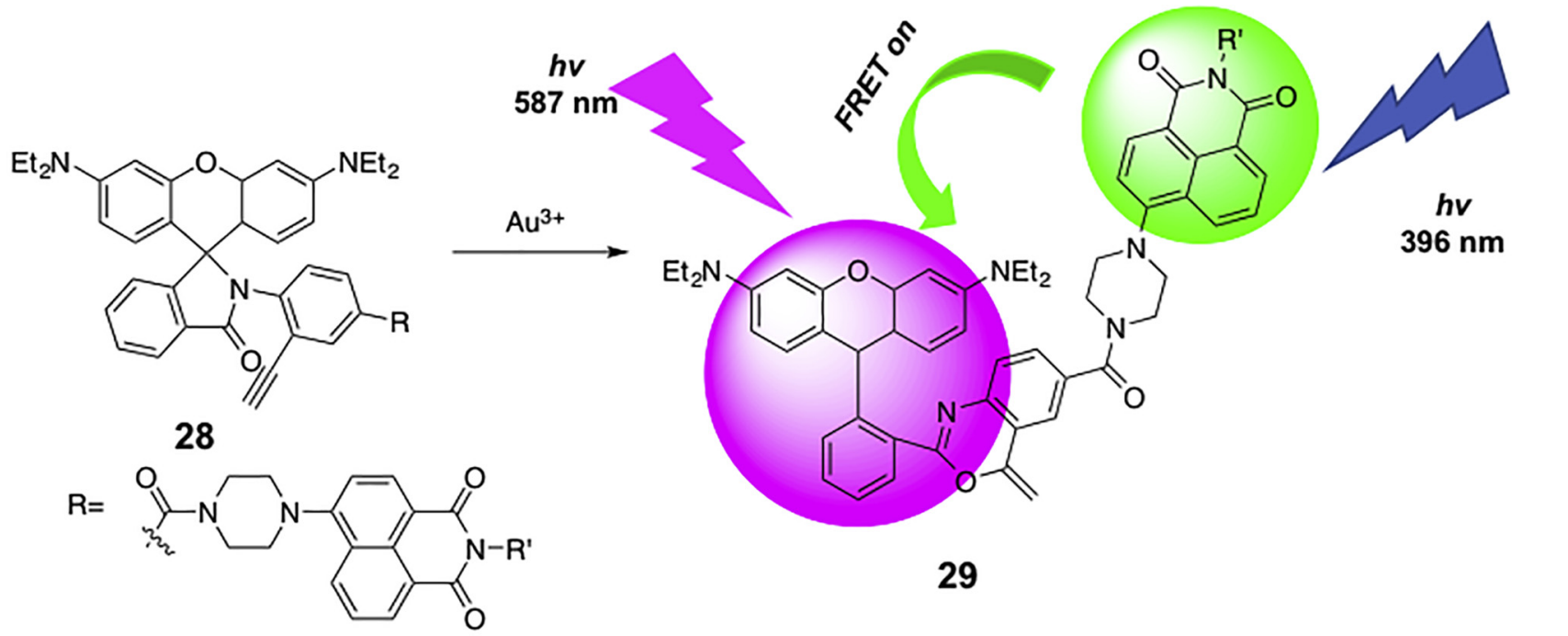

b)

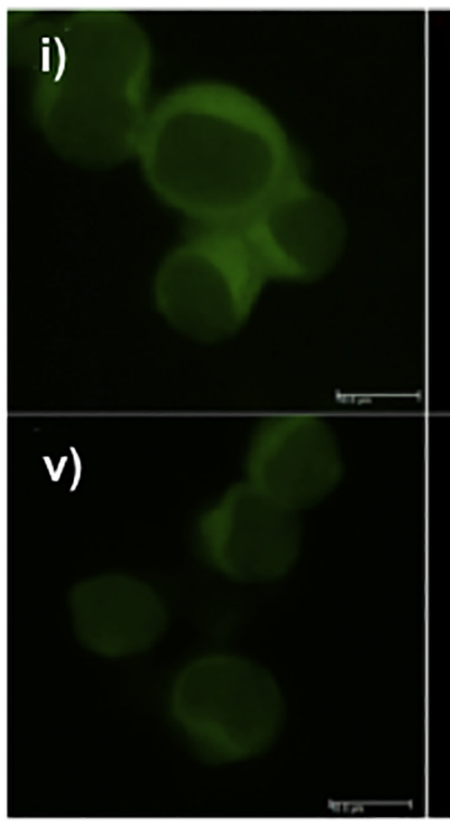

ii)

turnover of the catalytic process. Thus far, the best results for coupling a small azide with an alkyne in intracellular settings are those reported by Zimmerman et al. using Cu-MONPs. Considering the enormous effect of the coordinating ligands in the stability, reactivity, and toxicity of the copper complexes, one can foresee that novel ligands might provide redox stable $\mathrm{Cu}(\mathrm{I})$ complexes that could cross cell membranes efficiently, and therefore promote intracellular CuAAC reactions in an effective way.

\subsection{Gold}

Gold complexes have been broadly studied in bioinorganic chemistry and chemical biology for their bioactivity, mainly as anticancer agents. Specially, cyclometallated gold(III) complexes have been shown to elicit interesting pharmacological responses. Complexes featuring CN, CNN and CNC-type of ligands have been studied as protein inhibitors, DNA binders as well as promotors of intracellular redox damage [98,99]. Albeit less studied, gold(I) complexes with thiol, phosphine or NHC ligands have been also identified as anticancer agents [98].

However, the development of bioorthogonal transformations promoted by gold complexes is still in a very early stage. Indeed, the whole field of gold organometallic catalysis is quite young, since it was not until recently that the reactivity of gold ions was considered relevant [100-107]. The reactivity of $\mathrm{Au}(\mathrm{I})$ and $\mathrm{Au}(\mathrm{III})$ complexes is associated to their carbophilicity, in particular to the ability of these metals to coordinate and activate unsaturated bonds.

Of course, most reactions catalyzed by gold complexes have been reported in organic solvents, albeit some isolated transformations in aqueous media have also been described [108]. The translation of gold catalysis to biological media and cellular settings does not seem obvious, however there have been several reports on the development of sensing probes for gold ions in cellular envi- 
a)<smiles></smiles>

b)

ronments, mainly $\mathrm{Au}(\mathrm{III})$ salts, that rely on gold-promoted reactions.

In 2010, Kim and co-workers present some data on the viability of using a gold-promoted cyclization of designed alkynyl probes to provide fluorescent coumarin products (Scheme 8), however the cell biology part of manuscript is presented in a very preliminary way [109].

In 2014, Ahn and co-workers reported another strategy for sensing gold salts in cells based on a gold(III)-promoted oxa-cyclizations, with concomitant ring opening of a rhodamine-lactam ring (28). The sensing system included a donor dye derived from 1,8naphthalimide that generates a fluorescence resonance energy transfer (FRET) process with the rhodamine acceptor (29) (Fig. 17). The authors demonstrated that the probe can be used to detect gold salts purposely added to cells previously incubated with the alkyne precursor [110].

Recently, Tanaka and co-workers reported the development of a Glyco-Au(III) complex that appears to be able to promote a goldcatalyzed reaction in live mice. This $\mathrm{Au}(\mathrm{III})$ complex possess a 7diethylaminocoumarin linked to a water compatible cyclometalated

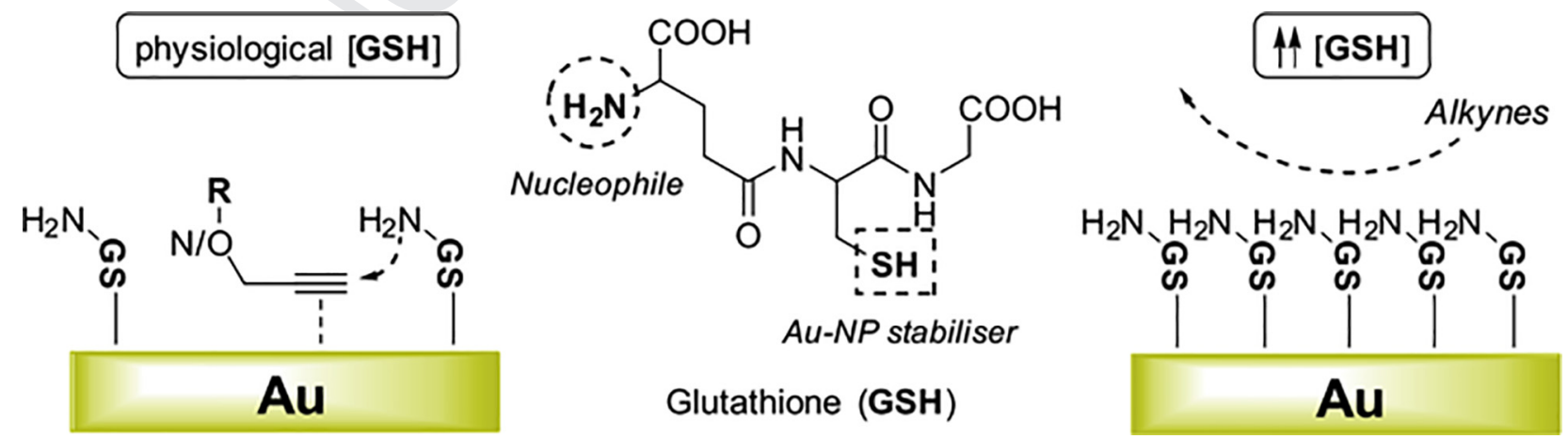

Fig. 19. Role of the GSH on the assistance/inhibition on the Au-mediated alkynyl-ester activation. Reproduced by permission [112] Copyright 2017, Wiley-VCH. 
Au(III) complex via a short PEG linker (30, Fig. 18a). This conjugate undergo a rapid translocation to target organs (i.e., liver, Glyco-Au (Sia); intestine, Glyco-Au (Gal)) thanks to an interaction with asparagine-linked glycans ( $\mathrm{N}$-glycans), and the resulting structures are capable of promoting an amide bond formation between fluorescent propargyl ester probes and nearby surface-protein amines (e.g., lysine side chains) (Fig. 18b) [111]. Despite the manuscript does not provide details on the catalytic part of the work, and lacks controls on the in vitro activity of the complexes, the work represents one of the first applications of an $\mathrm{Au}$ (III) catalytic complex in live mice, and thus opens new avenues on the potential applications of metal catalysis in biological research.

More recently, Unciti-Broceta and co-workers, described the preparation of gold nanoparticles (AuNPs, $30 \mathrm{~nm}$ ) supported within a PEG-grafted low-cross-linked polystyrene matrix (75 $\mu \mathrm{m}$ ), and their use for promoting the removal of propargyl protecting groups of a fluorogenic rhodamine [112]. It was possible to carry out the reaction in serum-free biological medium. This Auresin was also successfully tested in cell cultures media, albeit the transformations take place in the extracellular matrix; and even in vivo, using zebrafish as animal model.

The mechanistic studies carried out by the group suggest that, under physiological conditions, the deprotection reaction involves the activation of the alkyne by the gold surface, and the nucleophilic cooperative action of gold-tethered GSH. At higher concentrations of GSH, the reaction does not work, because the gold surface is fully packed with GSH molecules which inhibit the approach of the alkynes to the gold surface (Fig. 19).

Despite the progress in gold-promoted bioorthogonal reactions in biological media is yet weak, and the biological applications of gold catalysis are in their infancy, the distinctive reactivity of gold species with respect to other metals suggest that we will see soon new and relevant advances in the field.

\subsection{Iridium}

Most studies on the biological uses of Iridium organometallic complexes have been focused on the area of bioinorganic and medicinal chemistry, as well as in the development of imaging agents. The use of iridium complexes as catalysts in biological settings has been much more limited. The group of Sadler et al. has pioneered interesting studies on the viability of using organoiridium complexes as catalytic drugs inside cells, mainly for the controlled alteration of the $\mathrm{NADH} / \mathrm{NAD}^{+}$equilibrium $[42,43,113-$ 115]. They have designed iridium complexes which are capable of generating $\mathrm{H}_{2} \mathrm{O}_{2}$ by catalytic hydride transfer from the coenzyme NADH to oxygen. Some of these organoiridium complexes have even shown interesting anticancer potential owing to this ability to change the redox status of the cell.

Recently, the group of Do et al., developed iridium complexes which are able to promote aldehyde reductions in cell culture, through hydride transfer processes mediated by NADH [116]. The best results were obtained using iridium chloride complexes equipped with pentametylcyclopendienyl groups and chelating ligands like N-phenyl-2-pyridinecarboxamidate (Fig. 20a, complexes 31-33). These iridium catalysts are fairly stable under physiological conditions, tolerating moderate concentrations of biological nucleophiles such as GSH. The complexes are able to promote transfer hydrogenation processes in a versatile bioorthogonal way, which can be useful for the catalytic detoxification of disease-causing agents. The reduction processes can be monitored by fluorescence microscopy by using substrates such as BODIPYCHO (34), which upon reduction to its alcoholic form (BODIPY$\mathrm{OH},(35)$ ) experiment a change in the intensity of the fluorescence emission (Fig. 20b) [117].

The chemistry of Iridium catalysts in living cells has been essentially confined to hydride transfer modifications. Thus, the real challenge now lies on the translation to the biological medium of other type of iridium-mediated processes, including processes involving $\mathrm{C}-\mathrm{H}$ activations.

\subsection{Iron}

In contrast to $\mathrm{Pd}, \mathrm{Ru}, \mathrm{Au}$ or $\mathrm{Ir}$, iron is a transition metal very commonly used by nature, also for catalytic processes, but mainly in redox like transformations. The use of iron complexes to promote non-natural intracellular transformations with exogenous substrates has been rather limited. Indeed, to the best of our knowledge, there is only one example, published by Meggers et al., describing the use of an iron(III) 5,10,15,20-tetraphenyl-21 $\mathrm{H}, 23 \mathrm{H}$-porphine (TPP) complex [Fe(TPP)]Cl (36) to promote the reduction of the Rhodamine-bisazide 37 to rhodamine 110 (2) (Fig. 21) in HeLa cells [118]. The reaction can be monitored by fluorescence, owing to the increase in the emission of green light of the reduced probe. This experiment was also performed in vivo, using nematodes and zebrafish as animal models, and it was a)

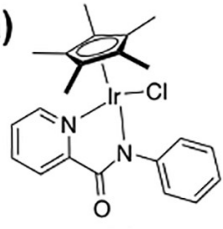

31
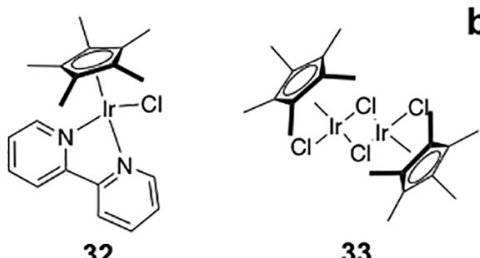

33
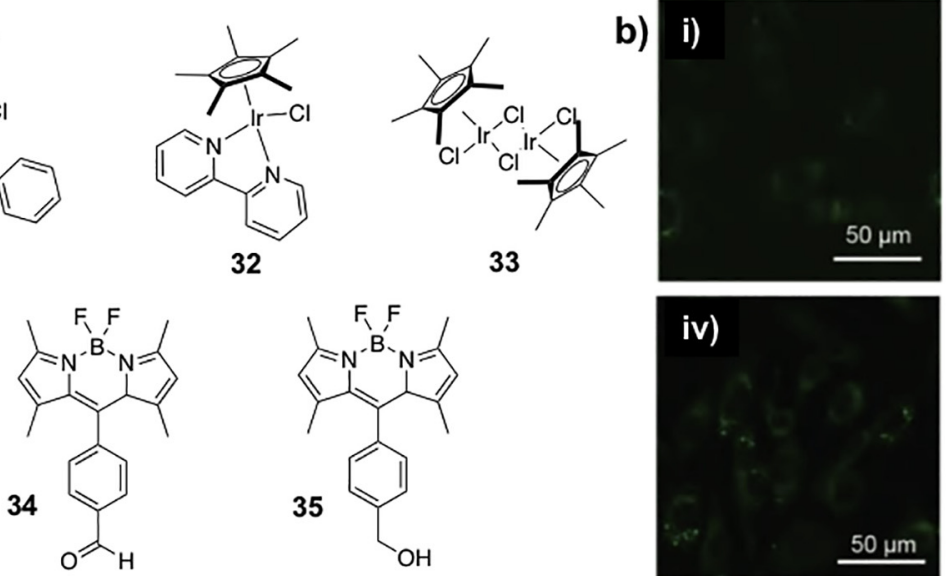

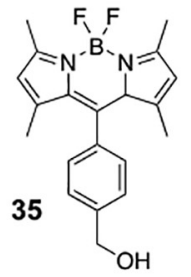

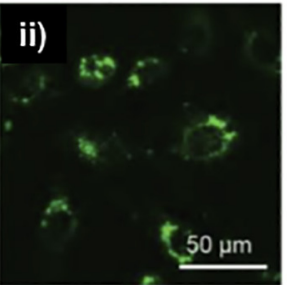
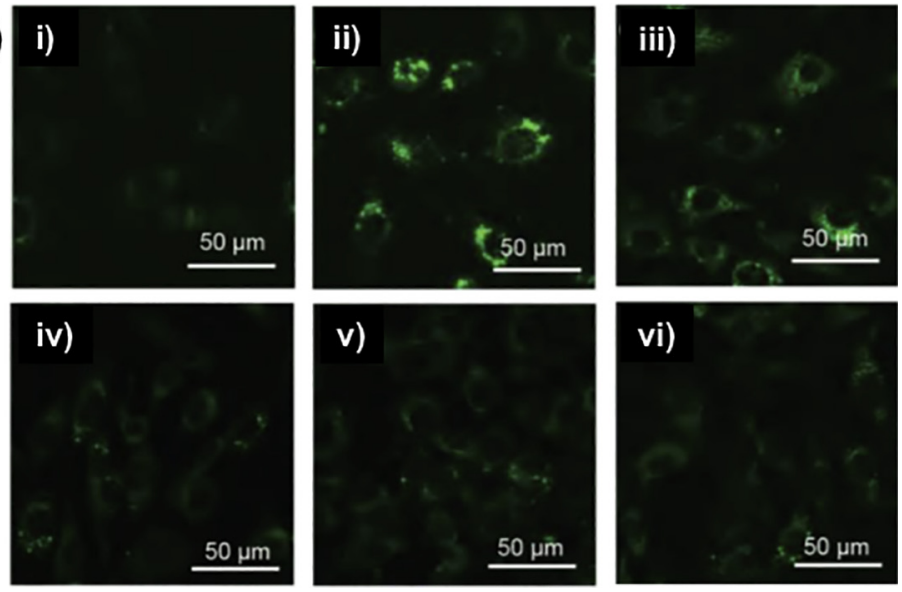

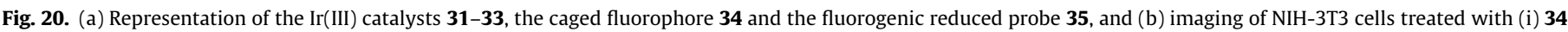

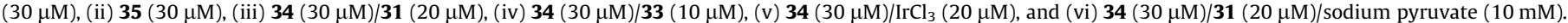

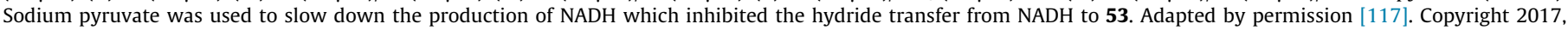
Wiley-VCH. 


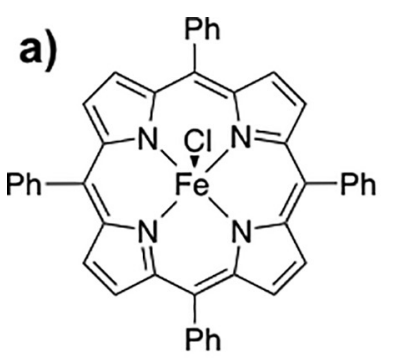

36 b)<smiles></smiles>

37<smiles>N=c1ccc2c(-c3ccccc3C(=O)[O-])c3ccc(N)cc3oc-2c1</smiles>

2

Fig. 21. (a) Fe complex used for the reduction reaction; and (b) iron-catalyzed reduction of the azide $\mathbf{3 7}$ to generate fluorescent product $\mathbf{2}$ [118].

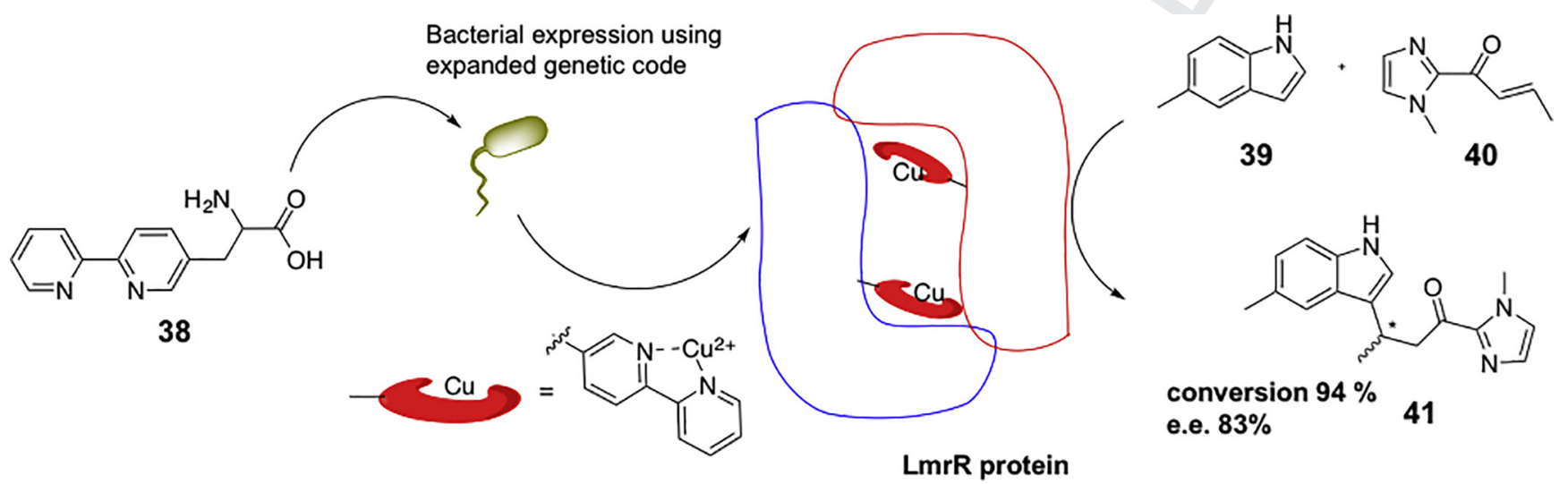

possible to observe how the green emission was spread out through the animal bodies. However, the authors later found out that most probably the fluorescence is arising from in vivo metabolic reduction of aromatic azides, not by the iron-mediated reduction.

\section{Artificial metalloenzymes}

Not surprisingly, the more efficient metal-catalyzed transformations in aqueous and biological media are those promoted by metalloenzymes, natural proteins equipped with metal cofactors in their active site. However, in most of these reactions the metal works either as a Lewis acid or as an electron transfer center, and does not engage in organometallic mechanisms typically found in other types of transition-metal catalysis (oxidative additions, reductive eliminations, migratory insertions...) [119].

Therefore, along recent years there has been a great interest in the development of metalloproteins that can achieve metal-based transformations which are not present in nature. Most of the work has been carried out in the context of asymmetric synthesis, albeit some preliminary examples on the development of mimetic of natural enzymes capable of working in living environments have been also developed. A number of detailed reviews in the area have been recently published [35-40], and therefore we will not provide a comprehensive review in this topic. Roelfes and co-workers published several reports on the engineering of non-natural protein catalysts by grafting non-proteinogenic amino acids capable of binding a transition-metals, and therefore provide an active site for different reactions. Thus, they built Bovine pancreatic polypeptide-Cu complexes (bPP-Cu(II)) which are able to promote Diels-Alder and Michael addition reactions in water, with enantioselectivities up to $86 \%$ [120]. Later, they grafted a new active site onto the dimer interface of the protein LmrR by introducing bidentate phenanthroline and bipyridine ligands capable of binding $\mathrm{Cu}(\mathrm{II})$ ions. The resulting metalloproteins allowed to improve the enantioselectivity of the Diels-Alder reaction up to 97\% enantiomeric excess (ee) [121]. In 2015 they also achieved Friedel-Crafts reactions of indoles, in water, with good enantioselectivity [122]. One year later, they were able to assemble a metalloenzyme in the context of the LmrR protein, incorporating a metal-binding non-proteinogenic amino acid (2,20-bipyridin-5yl) alanine (38), using gene expansion techniques. This represented the first example of an artificial metalloenzyme with an in vivo incorporated unnatural amino acid capable of binding a transition metal ion and catalyzing an enantioselective reaction (Scheme 9) [123].

Additional pioneering work on the development of non-natural metalloenzymes has been achieved by the group of Arnold, which among other advances, has been able to build modified cytochrome P450 proteins capable of promoting enantioselective cyclopropanations [124], and aziridinations of olefins [125]. Fasan and co-workers have also nicely contributed in this topic by the use of cytochrome P450 variants for the oxidation of $\mathrm{sp}^{3} \mathrm{C}-\mathrm{H}$ bonds [126], and for the amination of $\mathrm{sp}^{3} \mathrm{C}-\mathrm{H}$ bonds [127].

The group of Hartwig and co-workers, presented a nice strategy for the development of artificial metalloenzymes based on the replacement of the native metals of the protein cofactors by noble metals [128]. The designed systems elicited a totally different catalytic activity, and the selectivity of the reaction could be modulated by using directed evolution approaches. Thus, using heme proteins as scaffolds and Fe-porphyrin IX [Fe-PIX] as reference for the metal cofactor, they demonstrated that it is possible to 
a)<smiles>COC(=O)C(=N)c1ccccc1OC</smiles>

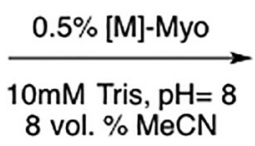
8 vol. \% MeCN<smiles>O=C(O)C1COc2ccccc21</smiles>

Yields up to $97 \%$ e.r. up to $92: 8$ c)

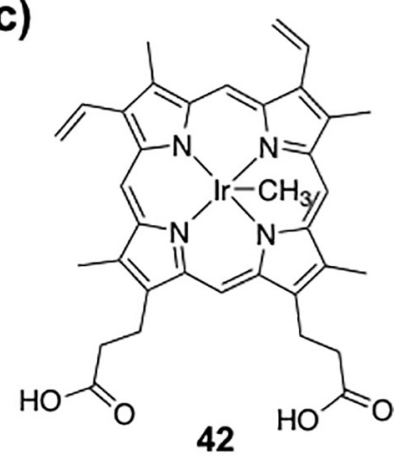

b)

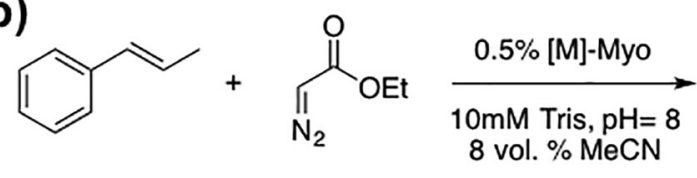<smiles>CCOC(=O)[C@H]1C(C)[C@H]1c1ccccc1</smiles>

e.r. up to $91: 9$ trans:cis ratio of $40: 1$

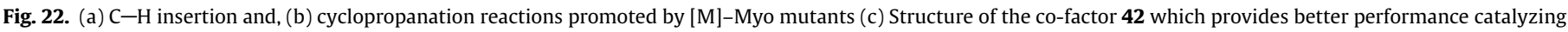
$\mathrm{C}-\mathrm{H}$ insertion and cyclopropanation reactions [128].

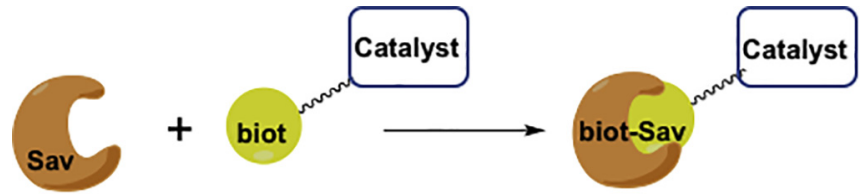

Scheme 10. Representation of the biot-Sav strategy for the formation of artificial metalloenzymes. substitute Fe by several noble metals ( $\mathrm{Fe}(\mathrm{Cl})-, \mathrm{Co}(\mathrm{Cl})-, \mathrm{Cu}-, \mathrm{Mn}(\mathrm{Cl})-$, $\mathrm{Rh}-, \operatorname{Ir}(\mathrm{Cl})-, \operatorname{Ir}(\mathrm{Me})-, \mathrm{Ru}(\mathrm{CO})-$ and $\mathrm{Ag}$-) to give novel type of metalloenzymes [128]. The methodology employed for the formation of these artificial metalloenzymes involved express directly and purify apo-PIX proteins lacking the entire heme unit, which is metals other than iron in a stoichiometric fashion. The strategy involved minimal media lacking Fe to minimize the bio-synthesis of hemin. This method indeed generated [M]-PIX-proteins with the intact active site and with the cofactors bound at the native PIX-binding site. These artificial metalloenzymes were evaluated for asymmetric $\mathrm{C}-\mathrm{H}$ insertion and cyclopropanation reactions using carbenes, under biological relevant conditions (10 mM Tris, reconstituted with the above derived metal cofactors containing
pH 8.0 containing 8 vol.\% MeCN) (Fig. 22). In the evaluation of these artificial myoglobins ([M]-Myo) as catalysts, they found that the [Ir(Me)-PIX] co-factor (42, Fig. 22) exhibited excellent performances with eight myoglobin mutants for both reactions. In the $\mathrm{C}-\mathrm{H}$ insertion reactions were obtained selectivities up to an enantiomeric ratio (e.r.) of 92:8 and with yields up to $97 \%$. In the cyclopropanations they obtained e.r. up to $91: 9$ and a trans:cis ratio of 40:1.

Further research by the same group has led to improved thermostable variant of cytochrome P450 from Sulfolobus solfatarius (CYP119) containing the cofactor 42. The carbene insertion was used again as model reaction. Several mutants from this artificial metalloenzyme were studied in a variety of carbene insertion reactions. In particular, mutants of the P450 enzyme $\operatorname{Ir}(\mathrm{Me})$-CYP119 containing 42 as cofactor catalyzed insertions of carbenes into $\mathrm{C}-\mathrm{H}$ bonds with excellent yields and up to $98 \%$ ee. The quadruple mutant of P450 Ir(Me)-CYP119-C317G-L69V-V254L (Ir(Me)-CYPMax) led to further improvements of both $k_{\text {cat }}$ and $K_{\mathrm{M}}$, creating an enzyme with an efficiency that improved up to 4000 -fold ( $k_{\text {cat }}$ $=45.8 \mathrm{~min}^{-1}, K_{\mathrm{M}}=0.17 \mathrm{mM}$, and $k_{\text {cat }} / K_{\mathrm{M}}=269 \mathrm{~min}^{-1} \mathrm{mM}^{-1}$ ) that of the $\operatorname{Ir}(\mathrm{Me})-\mathrm{CYP} 119$ system [129].

While most of this work deals with the use of the designed enzymes in asymmetric catalysis, preliminary attempts to build<smiles></smiles>

45<smiles>[O]P(CCNC(=O)CCCC[C@H]1SC[C@@H]2NC(=O)N[C@@H]21)(c1ccccc1)(c1ccccc1)c1ccccc1</smiles>

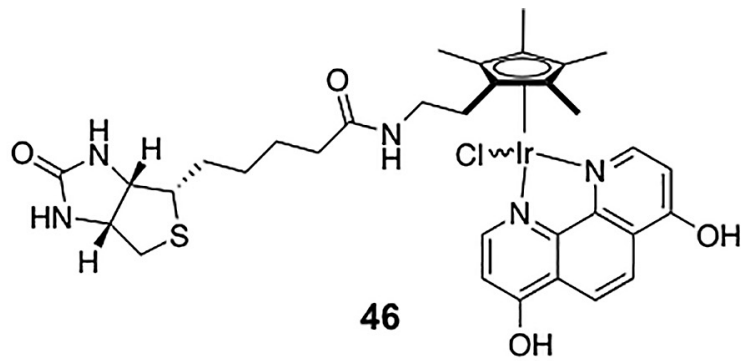

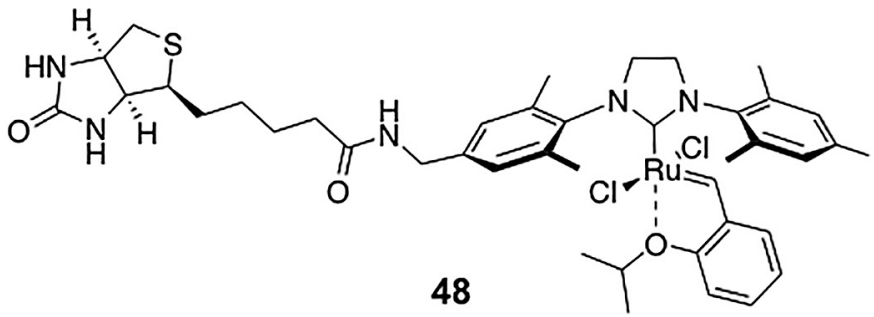

Fig. 23. Biotinylated complexes derived from Ir (45 [130,131] and $\mathbf{4 6}$ [132]), Pd (47 [133]) and Ru (48 [134]), used for the assembly of metalloenzymes by Ward and coworkers. 


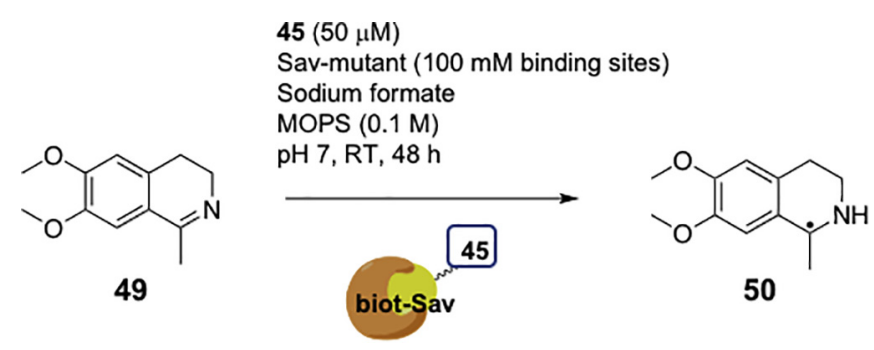

Scheme 11. Asymmetric reduction promoted by embedded 45 employing the biotSav strategy [131].

non-natural enzymes that can work in living environments are starting to be published. Perhaps the more relevant study has been recently reported by Ward and co-workers. This group has been pioneered on the use of biotin-streptavidin (biot-Sav, Scheme 10) interactions to build a variety of metalloenzymes equipped with metal catalysts [40]. Many of these hybrids perform very well in different type of transformations, including hydrogen transfer reactions by the incorporation of a $\mathrm{d}^{6}$-piano chair complexes within a host protein, [Cp*Ir(biot-p-L)Cl] (45) [130,131] and $\left[\left(\mathrm{Cp}^{*}\right.\right.$-biot $\left.) \operatorname{Ir}\left(\mathrm{L}^{\wedge} \mathrm{L}\right) \mathrm{Cl}\right]$ (46) [132] giving rise to artificial transfer hydrogenases (ATHase). The biot-Sav strategy has also been applied to other bioorthogonal reactions such as the SuzukiMiyaura Cross Coupling (using biot-Pd 47 as cofactor), affording an artificial Suzukiase for the synthesis of enantioenriched binaphthyls [133]. They have also built ruthenium-based metalloenzymes using biot-Ru 48, which were able to promote a metathesis reaction in the periplasm of E. coli (Fig. 23) [134].

The group has demonstrated that embedding an organometallic Iridium 45 complex within a host protein allows to overcome the poisoning of transition metal in living cells by the presence of thiols, mainly present in the form of GSH. The catalytic power of the Sav-complex with iridium complex 45 was evaluated ex cellulo, under different conditions, in the absence and in the presences of the Sav mutant, cell lysates and E. coli culture and in the presence of GSH neutralizing agents. While the free complex is capable to promote the racemic conversion of 6,7-dimethoxy-1-methyl-3,4dihydroisoquinoline (49) to salsolidine (50) with excellent yields, the presence of the mutant of the Sav S112A gave rise to excellent yields and more than $80 \%$ ee (Scheme 11) [131].
With regard to the metathesis reaction with organoruthenium complex 48; the authors demonstrated that this species is nearly inactive in cellulo, whereas the corresponding wild-type artificial metalloenzyme biot-Ru-Sav ${ }^{\text {peri }}$ endows the cell with metathesis activity in the periplasm of E. coli (Fig. 24) [134].

\section{Conclusions and closing remarks}

Achieving organometallic catalytic reactions of exogenous substrates in the complex aqueous environment of living cells and tissues is an enormous challenge. While the field is in its infancy, there is a steady increase in publications reporting new type of transformations in biological media and living cells. Therefore, while up to 2010 the reports were mainly limited to coppercatalyzed Click-type reactions, and only a few of them referring to the inside living cells all, of them up to 20 publications; after 2010 we have counted around 100 articles dealing with other metal-promoted transformations in biological media [30-33].

Promoting intracellular reactions is particularly difficult owing to the presence of a high concentration of components such as thiols or amines, which can poison the metal and kill the catalytic activity. Obtaining practical catalysts also require to deal with other issues such as cellular transport and side toxicity. In the future, it will be also needed to consider metal speciation, as well as analyze turnover and reaction rates inside cells.

Furthermore, other questions such as catalyst confinement within a specific organelle/environment, or the association of the catalytic complex with specific targets, remain to be addressed.

Despite all these difficulties, the enormous possibilities offered by organometallic chemistry, mainly because of the ligand variability that can be achieved, promises important future developments. Until know most of the advances have been essentially limited to copper-promoted azide-alkyne annulations, and to uncaging reactions triggered by ruthenium or palladium complexes. There is therefore enormous room for developing other type of transformations, such as cyclizations, coupling reactions, annulations or $\mathrm{C}-\mathrm{H}$ functionalizations, reactions that do not occur in nature. For instance, in this context, recent work in the $\mathrm{C}-\mathrm{H}$ functionalization of nucleobases in aqueous media might lead to future biological applications [135,136].

Advances in ligand design might lead to good ratios between reactivity and biological stability of the metal complexes, and even avoid the need to use nanostructure formulations for their deliv-

\section{a)}

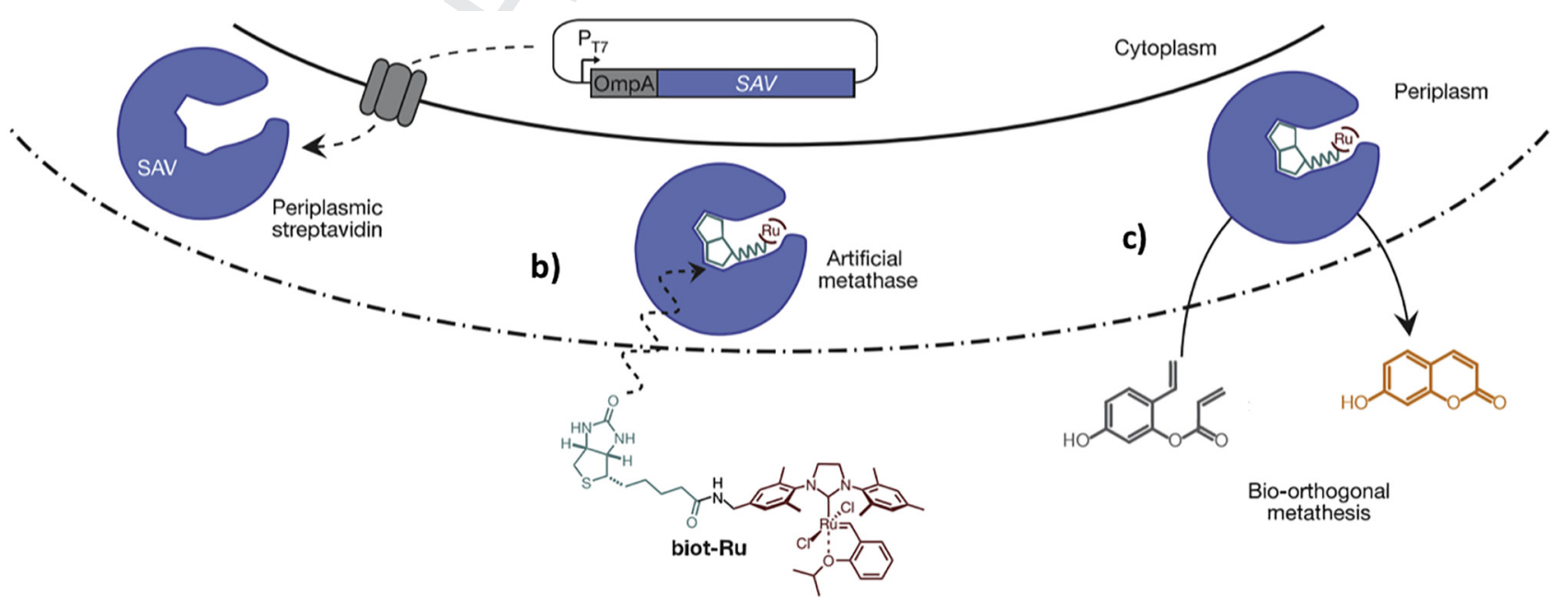

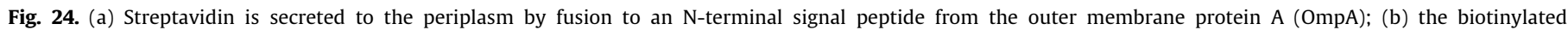

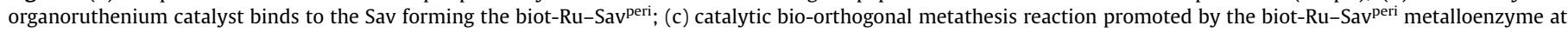
the periplasm of E. coli. Adapted with permission from [134], copyright 2017 Nature Publishing Group. 
ery. Nanoparticles are not exempt of problems derived from the protein corona effect and endosomal trapping; however, nanotechnology might also offer attractive opportunities in terms of transport, toxicity control and spatio-temporal triggering of the reactivity.

The expected progress in the field might therefore lead to important future applications in biological and medicinal chemistry.

Advances in this topic might allow for applications of the catalytic power of the organometallic complexes in medicinal chemistry. Additionally, the development of artificial metalloenzymes that can complement natural enzymes and therefore allow the construction of an artificial metabolism is other of the future challenges in the area.

\section{Competing financial interests}

The authors declare no competing financial interests.

\section{Acknowledgments}

We are thankful for the financial support from the Xunta de Galicia (Centro singular de investigación de Galicia accreditation 2016-2019) and the European Union (European Regional Development Fund - ERDF). We also thank support given by the Spanish grants sAF2013-41943-R and SAF2016-76689-R, the Xunta de Galicia (GRC2013-041 and 2015-CP082), the ERDF, and the European Research Council (Advanced Grant No. 340055). MMC thanks the Ministerio de Economía y Competitividad for the Postdoctoral fellowship (IJCI-2014-19326).

\section{References}

[1] R.H. Crabtree, Handbook of Green Chemistry, Green Catalysis, Heterogeneous Catalysis, WILEY-VCH Verlag (2009), https://doi.org/10.1595/ $147106710 \times 527928$.

[2] B. Cornils, W.A. Herrmann, Aqueous-phase Organometallic Catalysis Concepts and Applications, Second ed., WILEY-VCH, 2004.

[3] L.A. Schaper, S.J. Hock, W.A. Herrmann, F.E. Kühn, Synthesis and application of water-soluble NHC transition-metal complexes, Angew. Chem. Int. Ed. 52 (2013) 270-289, https://doi.org/10.1002/anie.201205119.

[4] C.-J. Li, T.-H. Chan, Comprehensive Organic Reactions in Aqueous Media, 2007. doi: http://doi.org/10.1002/9780470131442.

[5] U. Lindström, Organic reactions in water: principles, strategies and applications, Oleoscience (2007).

[6] Pierre H. Dixneuf, Victorio. Cadierno (Eds.), Metal-Catalyzed Reactions in Water, WILEY-VCH Verlag GmbH \& Co. KGaA, Weinheim, 2013.

[7] L.S. Hegedus, Transition metals in the synthesis of complex organic, Molecules (1999).

[8] P.-O. Norrby, Organotransition Metal Chemistry: From Bonding to Catalysis, John Hartwig, University Science Books, Sausalito, 2010, https://doi.org/ 10.1002/cctc.201000172.

[9] A. De Almeida, B.L. Oliveira, J.D.G. Correia, G. Soveral, A. Casini, Emerging protein targets for metal-based pharmaceutical agents: an update, Coord. Chem. Rev. 257 (2013) 2689-2704, https://doi.org/10.1016/j.ccr.2013.01.031.

[10] N. Feliu, D. Docter, M. Heine, P. Del Pino, S. Ashraf, J. Kolosnjaj-Tabi, P. Macchiarini, P. Nielsen, D. Alloyeau, F. Gazeau, R.H. Stauber, W.J. Parak, In vivo degeneration and the fate of inorganic nanoparticles, Chem. Soc. Rev. 45 (2016) 2440-2457, https://doi.org/10.1039/c5cs00699f.

[11] X. Wang, Z. Guo, Targeting and delivery of platinum-based anticancer drugs, Chem. Soc. Rev. 42 (2013) 202-224, https://doi.org/10.1039/c2cs35259a.

[12] M.R. Gill, J.A. Thomas, Ruthenium(II) polypyridyl complexes and DNA-From structural probes to cellular imaging and therapeutics, Chem. Soc. Rev. 41 (2012) 3179-3192, https://doi.org/10.1039/c2cs15299a.

[13] A. Levina, D.C. Crans, P.A. Lay, Speciation of metal drugs, supplements and toxins in media and bodily fluids controls in vitro activities, Coord. Chem. Rev. 352 (2017) 473-498, https://doi.org/10.1016/J.CCR.2017.01.002.

[14] K.A. Doucette, K.N. Hassell, D.C. Crans, Selective speciation improves efficacy and lowers toxicity of platinum anticancer and vanadium antidiabetic drugs, J. Inorg. Biochem. 165 (2016) 56-70, https://doi.org/10.1016/j. jinorgbio.2016.09.013.

[15] T.W. Hambley, Developing new metal-based therapeutics: challenges and opportunities, Dalton Trans. (2007) 4929-4937, https://doi.org/10.1039/ b706075k.

[16] M. Bottrill, L. Kwok, N.J. Long, Lanthanides in magnetic resonance imaging, Chem. Soc. Rev. 35 (2006) 557-571, https://doi.org/10.1039/b516376p.
[17] M. Patra, G. Gasser, Organometallic compounds: an opportunity for chemical biology?, ChemBioChem 13 (2012) 1232-1252, https://doiorg/10.1002/ cbic.201200159.

[18] S.J. Lippard, The inorganic side of chemical biology, Nat. Chem. Biol. 2 (2006) 504-507, https://doi.org/10.1038/nchembio1006-504.

[19] V.V. Rostovtsev, L.G. Green, V.V. Fokin, K.B. Sharpless, A stepwise Huisgen cycloaddition process: copper(I)-catalyzed regioselective "ligation" of azides and terminal alkynes, Angew. Chem. Int. Ed. 41 (2002) 2596-2599, doi: 10.1002/1521-3773(20020715)41:14<2596::AID-ANIE2596>3.0.CO;2-4.

[20] C.W. Tornøe, C. Christensen, M. Meldal, Peptidotriazoles on solid phase: $[1,2,3]$-triazoles by regiospecific copper(I)-catalyzed 1,3-dipolar cycloadditions of terminal alkynes to azides, J. Org. Chem. 67 (2002) 30573064, https://doi.org/10.1021/jo011148j.

[21] J.A. Prescher, D.H. Dube, C.R. Bertozzi, Chemical remodelling of cell surfaces in living animals, Nature 430 (2004) 873-877, https://doi.org/ 10.1038/nature02791.

[22] J.A. Prescher, C.R. Bertozzi, Chemistry in living systems, Nat. Chem. Biol. 1 (2005) 13-21, https://doi.org/10.1038/nchembio0605-13.

[23] C. Wu, Y. Jin, T. Schneider, D.R. Burnham, P.B. Smith, D.T. Chiu, Ultrabright and bioorthogonal labeling of cellular targets using semiconducting polymer dots and click chemistry, Angew. Chem. Int. Ed. 49 (2010) 9436-9440, https://doi. org/10.1002/anie.201004260.

[24] A. Dumont, A. Malleron, M. Awwad, S. Dukan, B. Vauzeilles, Click-mediated labeling of bacterial membranes through metabolic modification of the lipopolysaccharide inner core, Angew. Chem. Int. Ed. 51 (2012) 3143-3146, https://doi.org/10.1002/anie.201108127.

[25] M.A. Breidenbach, J.E.G. Gallagher, D.S. King, B.P. Smart, P. Wu, C.R. Bertozzi, Targeted metabolic labeling of yeast N-glycans with unnatural sugars, PNAS 107 (2010) 3988-3993, https://doi.org/10.1073/pnas.0911247107.

[26] C. Uttamapinant, A. Tangpeerachaikul, S. Grecian, S. Clarke, U. Singh, P. Slade, K.R. Gee, A.Y. Ting Fast, Cell-compatible click chemistry with copperchelating azides for biomolecular labeling, Angew. Chem. Int. Ed. 51 (2012) 5852-5856, https://doi.org/10.1002/anie.201108181.

[27] C. Streu, E. Meggers, Ruthenium-induced allylcarbamate cleavage in living cells, Angew. Chem. Int. Ed. 45 (2006) 5645-5648, https://doi.org/10.1002/ anie.200601752.

[28] R.M. Yusop, A. Unciti-Broceta, E.M. Johansson, R.M. Sanchez-Martin, M. Bradley, Palladium-mediated intracellular chemistry, Nat. Chem. 3 (2011) 239-243, https://doi.org/10.1038/nchem.981.

[29] J. Li, J. Yu, J. Zhao, J. Wang, S. Zheng, S. Lin, L. Chen, M. Yang, S. Jia, X. Zhang, P. R. Chen, Palladium-triggered deprotection chemistry for protein activation in living cells, Nat. Chem. 6 (2014) 352-361, https://doi.org/10.1038/ nchem. 1887.

[30] P.K. Sasmal, C.N. Streu, E. Meggers, Metal complex catalysis in living biological systems, Chem. Commun. 49 (2013) 1581-1587, https://doi.org/ 10.1039/c2cc37832a.

[31] S.V. Chankeshwara, E. Indrigo, M. Bradley, Palladium-mediated chemistry in living cells, Curr. Opin. Chem. Biol. 21 (2014) 128-135, https://doi.org/ 10.1016/j.cbpa.2014.07.007.

[32] M. Yang, J. Li, P.R. Chen, Transition metal-mediated bioorthogonal protein chemistry in living cells, Chem. Soc. Rev. 43 (2014) 6511, https://doi.org/ 10.1039/C4CS00117F.

[33] T. Völker, E. Meggers, Transition-metal-mediated uncaging in living human cells-an emerging alternative to photolabile protecting groups, Curr. Opin. Chem. Biol. 25 (2015) 48-54, https://doi.org/10.1016/j.cbpa.2014.12.021.

[34] M. Jbara, S.K. Maity, A. Brik, Palladium in the chemical synthesis and modification of proteins, Angew. Chem. Int. Ed. 56 (2017) 10644-10655, https://doi.org/10.1002/anie.201702370.

[35] P.J. Deuss, R. Denheeten, W. Laan, P.C.J. Kamer, Bioinspired catalyst design and artificial metalloenzymes, Chem. Eur. J. 17 (2011) 4680-4698, https:// doi.org/10.1002/chem.201003646.

[36] M.R. Ringenberg, T.R. Ward, Merging the best of two worlds: artificial metalloenzymes for enantioselective catalysis, Chem. Commun. (Camb.) 47 (2011) 8470-8476, https://doi.org/10.1039/c1cc11592h.

[37] M. Dürrenberger, T.R. Ward, Recent achievements in the design and engineering of artificial metalloenzymes, Curr. Opin. Chem. Biol. 19 (2014) 99-106, https://doi.org/10.1016/j.cbpa.2014.01.018.

[38] T.K. Hyster, T.R. Ward, Genetic optimization of metalloenzymes: enhancing enzymes for non-natural reactions, Angew. Chem. Int. Ed. 55 (2016) 73447357, https://doi.org/10.1002/anie.201508816.

[39] T. Heinisch, T.R. Ward, Latest developments in metalloenzyme design and repurposing, Eur. J. Inorg. Chem. 2015 (2015) 3406-3418, https://doi.org/ 10.1002/ejic.201500408.

[40] F. Schwizer, Y. Okamoto, T. Heinisch, Y. Gu, M.M. Pellizzoni, V. Lebrun, R. Reuter, V. Köhler, J.C. Lewis, T.R. Ward, Artificial metalloenzymes: reaction scope and optimization strategies, Chem. Rev. (2017), https://doi.org/ 10.1021/acs.chemrev.7b00014, acs.chemrev.7b00014.

[41] G. Sava, A. Bergamo, P.J. Dyson, Metal-based antitumour drugs in the postgenomic era: what comes next?, Dalton Trans 40 (2011) 9069, https://doi. org/10.1039/c1dt10522a.

[42] S.J. Dougan, A. Habtemariam, S.E. McHale, S. Parsons, P.J. Sadler, Catalytic organometallic anticancer complexes, Proc. Natl. Acad. Sci. U.S.A. 105 (2008) 11628-11633, https://doi.org/10.1073/pnas.0800076105.

[43] J.J. Soldevila-Barreda, I. Romero-Canelón, A. Habtemariam, P.J. Sadler, Transfer hydrogenation catalysis in cells as a new approach to anticancer 
drug design, Nat. Commun. 6 (2015) 6582, https://doi.org/10.1038/ ncomms7582.

[44] P.K. Sasmal, S. Carregal-Romero, W.J. Parak, E. Meggers, Light-triggered ruthenium-catalyzed allylcarbamate cleavage in biological environments, Organometallics 31 (2012) 5968-5970, https://doi.org/10.1021/om3001668.

[45] O. Vázquez, M.I. Sánchez, J. Martínez-Costas, M.E. Vázquez, J.L. Mascareñas, Bis-4-aminobenzamidines: versatile, fluorogenic A/T-selective dsDNA binders, Org. Lett. 12 (2010) 216-219, https://doi.org/10.1021/ol902501j.

[46] M.I. Sánchez, C. Penas, M.E. Vázquez, J.L. Mascareñas, Metal-catalyzed uncaging of DNA-binding agents in living cells, Chem. Sci. 5 (2014) 19011907, https://doi.org/10.1039/c3sc53317d.

[47] S. Tanaka, H. Saburi, Y. Ishibashi, M. Kitamura, CpRuIIPF6/quinaldic acidcatalyzed chemoselective allyl ether cleavage. A simple and practical method for hydroxyl deprotection, Org. Lett. 6 (2004) 1873-1875, https://doi.org/ 10.1021/ol0493397.

[48] H. Saburi, S. Tanaka, M. Kitamura, Catalytic dehydrative allylation of alcohols, Angew. Chem. Int. Ed. 44 (2005) 1730-1732, https://doi.org/10.1002/ anie.200462513.

[49] T. Völker, F. Dempwolff, P.L. Graumann, E. Meggers, Progress towards bioorthogonal catalysis with organometallic compounds, Angew. Chem. Int. Ed. 53 (2014) 10536-10540, https://doi.org/10.1002/anie.201404547.

[50] H.-T. Hsu, B.M. Trantow, R.M. Waymouth, P.A. Wender, Bioorthogonal catalysis: a general method to evaluate metal-catalyzed reactions in real time in living systems using a cellular luciferase reporter system, Bioconjug. Chem. $27 \quad$ (2015) 376-382, https://doi.org/10.1021/acs. bioconjchem.5b00469.

[51] M. Tomás-Gamasa, M. Martínez-Calvo, J.R. Couceiro, J.L. Mascareñas, Transition metal catalysis in the mitochondria of living cells, Nat. Commun. 7 (2016) 12538, https://doi.org/10.1038/ncomms12538.

[52] M.P. Murphy, Targeting lipophilic cations to mitochondria, Biochim. Biophys. Acta, Bioenerg. 1777 (2008) 1028-1031, https://doi.org/10.1016/j. bbabio.2008.03.029.

[53] T. Völker, E. Meggers, Chemical activation in blood serum and human cell culture: improved ruthenium complex for catalytic uncaging of allocprotected amines, ChemBioChem 18 (2017) 1083-1086, https://doi.org/ 10.1002/cbic.201700168.

[54] P. Destito, J.R. Couceiro, H. Faustino, F. López, J.L. Mascareñas, Rutheniumcatalyzed azide-thioalkyne cycloadditions in aqueous media: a mild, orthogonal, and biocompatible chemical ligation, Angew. Chem., Int. Ed. 56 (2017) 10766-10770, https://doi.org/10.1002/anie.201705006.

[55] K.C. Nicolaou, P.G. Bulger, D. Sarlah, Palladium-catalyzed cross-coupling reactions in total synthesis, Angew. Chem., Int. Ed. 44 (2005) 4442-4489, https://doi.org/10.1002/anie.200500368.

[56] J.M. Chalker, C.S.C. Wood, B.G. Davis, A convenient catalyst for aqueous and protein Suzuki-Miyaura cross-coupling, J. Am. Chem. Soc. 131 (2009) 1634616347, https://doi.org/10.1021/ja907150m.

[57] C.D. Spicer, B.G. Davis, Palladium-mediated site-selective Suzuki-Miyaura protein modification at genetically encoded aryl halides, Chem. Commun. 47 (2011) 1698-1700, https://doi.org/10.1039/c0cc04970k.

[58] J.-H. Li, X.-D. Zhang, Y.-X. Xie, Efficient and copper-free sonogashira crosscoupling reaction catalyzed by $\mathrm{Pd}(\mathrm{OAc})_{2} /$ pyrimidines catalytic system, Eur. J. Org. Chem. 2005 (2005) 4256-4259, https://doi.org/10.1002/ejoc.200500519.

[59] K. Sonogashira, Y. Tohda, N. Hagihara, A convenient synthesis of acetylenes: catalytic substitutions of acetylenic hydrogen with bromoalkenes, iodoarenes and bromopyridines, Tetrahedron Lett. 16 (1975) 4467-4470, https://doi.org/ 10.1016/S0040-4039(00)91094-3.

[60] N. Miyaura, A. Suzuki, Stereoselective synthesis of arylated (E)-alkenes by the reaction of alk-1-enylboranes with aryl halides in the presence of palladium catalyst, J. Chem. Soc., Chem. Commun. (1979) 866, https://doi.org/10.1039/ c39790000866.

[61] N. Miyaura, K. Yamada, A. Suzuki, A new stereospecific cross-coupling by the palladium-catalyzed reaction of 1-alkenylboranes with 1-alkenyl or 1alkynyl halides, Tetrahedron Lett. 20 (1979) 3437-3440, https://doi.org/ 10.1016/S0040-4039(01)95429-2.

[62] Z. Gao, V. Gouverneur, B.G. Davis, Enhanced aqueous Suzuki-Miyaura coupling allows site-specific polypeptide ${ }^{18} \mathrm{~F}$-labeling, J. Am. Chem. Soc. 135 (2013) 13612-13615, https://doi.org/10.1021/ja4049114.

[63] C.D. Spicer, T. Triemer, B.G. Davis, Palladium-mediated cell-surface labeling, J. Am. Chem. Soc. 134 (2012) 800-803, https://doi.org/10.1021/ja209352s.

[64] N. Li, R.K.V. Lim, S. Edwardraja, Q. Lin, Copper-free sonogashira cross-coupling for functionalization of alkyne-encoded proteins in aqueous medium and in bacterial cells, J. Am. Chem. Soc. 133 (2011) 15316-15319, https://doi.org/ $10.1021 /$ ja2066913.

[65] R.K.V. Lim, N. Li, C.P. Ramil, Q. Lin, Fast and sequence-specific palladiummediated cross-coupling reaction identified from phage display, ACS Chem. Biol. 9 (2014) 2139-2148, https://doi.org/10.1021/cb500443x.

[66] N. Li, C.P. Ramil, R.K.V. Lim, Q. Lin, A genetically encoded alkyne directs palladium-mediated protein labeling on live mammalian cell surface, ACS Chem. Biol. 10 (2015) 379-384, https://doi.org/10.1021/cb500649q.

[67] J. Wang, B. Cheng, J. Li, Z. Zhang, W. Hong, X. Chen, P.R. Chen, Chemical remodeling of cell-surface sialic acids through a palladium-triggered bioorthogonal elimination reaction, Angew. Chem. Int. Ed. 54 (2015) 53645368, https://doi.org/10.1002/anie.201409145.

[68] J. Wang, S. Zheng, Y. Liu, Z. Zhang, Z. Lin, J. Li, G. Zhang, X. Wang, J. Li, P.R. Chen, Palladium-triggered chemical rescue of intracellular proteins via genetically encoded allene-caged tyrosine, J. Am. Chem. Soc. (2016), https:// doi.org/10.1021/jacs.6b08933, jacs.6b08933.

[69] E. Ramirez, S. Jansat, K. Philippot, P. Lecante, M. Gomez, A.M. Masdeu-Bultó, B. Chaudret, Influence of organic ligands on the stabilization of palladium nanoparticles, J. Organomet. Chem. 689 (2004) 4601-4610, https://doi.org/ 10.1016/j.jorganchem.2004.09.006.

[70] C.S. Wei, G.H.M. Davies, O. Soltani, J. Albrecht, Q. Gao, C. Pathirana, Y. Hsiao, S. Tummala, M.D. Eastgate, The impact of palladium(II) reduction pathways on the structure and activity of palladium(0) catalysts, Angew. Chem., Int. Ed. 52 (2013) 5822-5826, https://doi.org/10.1002/anie.201210252.

[71] A.H.M. de Vries, J.M.C.A. Mulders, J.H.M. Mommers, H.J.W. Henderickx, J.G. de Vries, Homeopathic ligand-free palladium as a catalyst in the heck reaction. A comparison with a palladacycle, Org. Lett. 5 (2003) 3285-3288, https://doi. org/10.1021/ol035184b.

[72] A.J. Deangelis, P.G. Gildner, R. Chow, T.J. Colacot, Generating active "L-Pd(0)" via neutral or cationic $\pi$-allylpalladium complexes featuring biaryl/ bipyrazolylphosphines: synthetic, mechanistic, and structure-activity studies in challenging cross-coupling reactions, J. Org. Chem. 80 (2015) 6794-6813, https://doi.org/10.1021/acs.joc.5b01005.

[73] I. Schmid, C.H. Uittenbogaart, J.V. Giorgi, A gentle fixation and permeabilization method for combined cell surface and intracellular staining with improved precision in DNA quantification, Cytometry 12 (1991) 279-285, https://doi.org/10.1002/cyto.990120312.

[74] J.T. Weiss, J.C. Dawson, C. Fraser, W. Rybski, C. Torres-Sánchez, M. Bradley, E. E. Patton, N.O. Carragher, A. Unciti-Broceta, Development and bioorthogonal activation of palladium-labile prodrugs of gemcitabine, J. Med. Chem. 57 (2014) 5395-5404, https://doi.org/10.1021/jm500531z.

[75] B. Rubio-Ruiz, J.T. Weiss, A. Unciti-Broceta, Efficient palladium-triggered release of vorinostat from a bioorthogonal precursor, J. Med. Chem. 59 (2016) 9974-9980, https://doi.org/10.1021/acs.jmedchem.6b01426.

[76] J.T. Weiss, J.C. Dawson, K.G. Macleod, W. Rybski, C. Fraser, C. Torres-Sánchez, E.E. Patton, M. Bradley, N.O. Carragher, A. Unciti-Broceta, Extracellular palladium-catalysed dealkylation of 5-fluoro-1-propargyl-uracil as a bioorthogonally activated prodrug approach, Nat. Commun. 5 (2014) 3277, https://doi.org/10.1038/ncomms4277.

[77] E. Indrigo, J. Clavadetscher, S.V. Chankeshwara, A. Lilienkampf, M. Bradley, Palladium-mediated in situ synthesis of an anticancer agent, Chem. Commun 52 (2016) 14212-14214, https://doi.org/10.1039/C6CC08666G.

[78] J. Clavadetscher, E. Indrigo, S.V. Chankeshwara, A. Lilienkampf, M. Bradley, Incell dual drug synthesis by cancer-targeting palladium catalysts, Angew. Chem., Int. Ed. 56 (2017) 6864-6868, https://doi.org/10.1002/ anie.201702404.

[79] E. Indrigo, J. Clavadetscher, S.V. Chankeshwara, A. Megia-Fernandez, A Lilienkampf, M. Bradley, L. Chen, M. Yang, S. Jia, X. Zhang, P.R. Chen, Intracellular delivery of a catalytic organometallic complex, Chem. Commun. 278 (2017) 31192-31201, https://doi.org/10.1039/C7CC02988H.

[80] M.A. Miller, B. Askevold, H. Mikula, R.H. Kohler, D. Pirovich, R. Weissleder, Nano-palladium is a cellular catalyst for in vivo chemistry, Nat. Commun. 8 (2017), https://doi.org/10.1038/ncomms15906.

[81] Y. Chen, M. Zhang, Y. Han, J. Wei, C.-H. Chen, D. Lee, Y. Han, M.R. Uddin, S Goswami, C.K. Quah, H.-K. Fun, A depropargylation-triggered spontaneous cyclization based fluorescent "turn-on" chemodosimeter for the detection of palladium ions and its application in live-cell imaging, RSC Adv. 6 (2016) 8380-8383, https://doi.org/10.1039/C5RA23645B.

[82] H. Chen, W. Lin, L. Yuan, W. Gao, B. Chen, L. He, S. Zhu, M. Yin, B. Tang, Construction of a near-infrared fluorescence turn-on and ratiometric probe for imaging palladium in living cells, Org. Biomol. Chem. 11 (2013) 1938 https://doi.org/10.1039/c3ob27507h.

[83] F. Huo, Y. Zhang, J. Kang, J. Chao, Y. Zhang, C. Yin, A novel alkyne compound as a $\mathrm{Pd}(\mathrm{II})$ fluorescent probe in aqueous medium and its bioimaging, Sens. Actuators, B: Chem. 243 (2017) 429-434, https://doi.org/10.1016/j. snb.2016.11.034

[84] W. Liu, J. Jiang, C. Chen, X. Tang, J. Shi, P. Zhang, K. Zhang, Z. Li, W. Dou, L. Yang, W. Liu, Water-soluble colorimetric and ratiometric fluorescent probe for selective imaging of palladium species in living cells, Inorg. Chem. 53 (2014) 12590-12594, https://doi.org/10.1021/ic502223n.

[85] V. Hong, N.F. Steinmetz, M. Manchester, M.G. Finn, Labeling live cells by copper-catalyzed alkyne-azide click chemistry, Bioconjug. Chem. 21 (2010) 1912-1916, https://doi.org/10.1021/bc100272z.

[86] D.C. Kennedy, C.S. McKay, M.C.B. Legault, D.C. Danielson, J.A. Blake, A.F. Pegoraro, A. Stolow, Z. Mester, J.P. Pezacki, Cellular consequences of copper complexes used to catalyze bioorthogonal click reactions, J. Am. Chem. Soc. 133 (2011) 17993-18001, https://doi.org/10.1021/ja2083027.

[87] C. Besanceney-Webler, H. Jiang, T. Zheng, L. Feng, D. Soriano del Amo, W. Wang, L.M. Klivansky, F.L. Marlow, Y. Liu, P. Wu, Increasing the efficacy of bioorthogonal click reactions for bioconjugation: a comparative study, Angew. Chem. Int. Ed. 50 (2011) 8051-8056, https://doi.org/10.1002/ anie.201101817.

[88] V. Hong, S.I. Presolski, C. Ma, M.G. Finn, Analysis and optimization of coppercatalyzed azide-alkyne cycloaddition for bioconjugation, Angew. Chem., Int. Ed. 48 (2009) 9879-9883, https://doi.org/10.1002/anie.200905087.

[89] A.J. Link, D.A. Tirrell, Cell surface labeling of Escherichia coli via copper(I)catalyzed [3+2] cycloaddition, J. Am. Chem. Soc. 125 (2003) 11164-11165, https://doi.org/10.1021/ja036765z. 
[90] A.J. Link, M.K.S. Vink, D.A. Tirrell, Presentation and detection of azide functionality in bacterial cell surface proteins, J. Am. Chem. Soc. 126 (2004) 10598-10602, https://doi.org/10.1021/ja047629c.

[91] K.E. Beatty, J.C. Liu, F. Xie, D.C. Dieterich, E.M. Schuman, Q. Wang, D.A. Tirrell, Fluorescence visualization of newly synthesized proteins in mammalian cells, Angew. Chem., Int. Ed. 45 (2006) 7364-7367, https://doi.org/10.1002/ anie.200602114.

[92] M. Yang, Y. Song, M. Zhang, S. Lin, Z. Hao, Y. Liang, D. Zhang, P.R. Chen, Converting a solvatochromic fluorophore into a protein-based $\mathrm{pH}$ indicator for extreme acidity, Angew. Chem., Int. Ed. 51 (2012) 7674-7679, https://doi. org/10.1002/anie.201204029.

[93] M. Yang, A.S. Jalloh, W. Wei, J. Zhao, P. Wu, P.R. Chen, Biocompatible click chemistry enabled compartment-specific $\mathrm{pH}$ measurement inside E. coli, Nat. Commun. 5 (2014) 4981, https://doi.org/10.1038/ncomms5981.

[94] V. Bevilacqua, M. King, M. Chaumontet, M. Nothisen, S. Gabillet, D. Buisson, C. Puente, A. Wagner, F. Taran, Copper-chelating azides for efficient click conjugation reactions in complex media, Angew. Chem. Int. Ed. 53 (2014) 5872-5876, https://doi.org/10.1002/anie.201310671.

[95] S. Li, L. Wang, F. Yu, Z. Zhu, D. Shobaki, H. Chen, M. Wang, J. Wang, G. Qin, U.J. Erasquin, L. Ren, Y. Wang, C. Cai, Copper-catalyzed click reaction on/in live cells, Chem. Sci. 8 (2017) 2107-2114, https://doi.org/10.1039/C6SC02297A.

[96] J. Clavadetscher, S. Hoffmann, A. Lilienkampf, L. Mackay, R.M. Yusop, S.A Rider, J.J. Mullins, M. Bradley, Copper catalysis in living systems and in situ drug synthesis, Angew. Chem., Int. Ed. 55 (2016) 15662-15666, https://doi. org/10.1002/anie.201609837.

[97] Y. Bai, X. Feng, H. Xing, Y. Xu, B.K. Kim, N. Baig, T. Zhou, A.A. Gewirth, Y. Lu, E. Oldfield, S.C. Zimmerman, A highly efficient single-chain metal-organic nanoparticle catalyst for alkyne-azide "click" reactions in water and in cells, J. Am. Chem. Soc. 138 (2016) 11077-11080, https://doi.org/ 10.1021 /jacs.6b04477.

[98] T. Zou, C.T. Lum, C.-N. Lok, J.-J. Zhang, C.-M. Che, Chemical biology of anticancer gold(III) and gold(I) complexes, Chem. Soc. Rev. 44 (2015) 87868801, https://doi.org/10.1039/C5CS00132C.

[99] B. Bertrand, A. Casini, A golden future in medicinal inorganic chemistry: the promise of anticancer gold organometallic compounds, Dalton Trans. 43 (2014) 4209-4219, https://doi.org/10.1039/C3DT52524D.

[100] D.J. Gorin, B.D. Sherry, F.D. Toste, Ligand effects in homogeneous Au catalysis, Chem. Rev. 108 (2008) 3351-3378, https://doi.org/10.1021/cr068430g.

[101] E. Jiménez-Núñez, A.M. Echavarren, Gold-catalyzed cycloisomerizations of enynes: a mechanistic perspective, Chem. Rev. 108 (2008) 3326-3350, https://doi.org/10.1021/cr0684319.

[102] A. Arcadi, Alternative synthetic methods through new developments in catalysis by gold, Chem. Rev. 108 (2008) 3266-3325, https://doi.org/10.1021/ cr068435d.

[103] Z. Li, C. Brouwer, C. He, Gold-catalyzed organic transformations, Chem. Rev. 108 (2008) 3239-3265, https://doi.org/10.1021/cr068434l.

[104] A. Fürstner, E. Beckmann, B.J. Burke, A. Boyer, S.L. Maslen, S.V. Ley, L. Fensterbank, M. Malacria, D.J. Cárdenas, A.M. Echavarren, Gold and platinum catalysis-A convenient tool for generating molecular complexity, Chem. Soc. Rev. 38 (2009) 3208, https://doi.org/10.1039/b816696j.

[105] A. Corma, A. Leyva-Pérez, M.J. Sabater, Gold-catalyzed carbon-heteroatom bond-forming reactions, Chem. Rev. 111 (2011) 1657-1712, https://doi.org/ $10.1021 / \mathrm{cr} 100414 \mathrm{u}$.

[106] F. López, J.L. Mascareñas, Gold(I)-catalyzed enantioselective cycloaddition reactions, Beilstein J. Org. Chem. 9 (2013) 2250-2264, https://doi.org 10.3762/bjoc.9.264.

[107] J.L. Mascareñas, F. López, Synthesis of oxygenated heterocyclic compounds via gold-catalyzed functionalization of $\pi$-systems, in: Top. Organomet. Chem., Springer, Cham, 2016, pp. 1-52, https://doi.org/10.1007/ 7081_2015_5006.

[108] V. Cadierno, J. García-Álvarez, S.E. García-Garrido, Catalytic rearrangements and allylation reactions in water, Met. React. Water (2013) 243-289, https:// doi.org/10.1002/9783527656790.ch7.

[109] J.H. Do, H.N. Kim, J. Yoon, J.S. Kim, H.-J. Kim, A rationally designed fluorescence turn-on probe for the gold(III) ion, Org. Lett. 12 (2010) 932 934, https://doi.org/10.1021/ol902860f.

[110] H. Seo, M.E. Jun, K. Ranganathan, K.H. Lee, K.T. Kim, W. Lim, Y.M. Rhee, K.H. Ahn, Ground-state elevation approach to suppress side reactions in goldsensing systems based on alkyne activation, Org. Lett. 16 (2014) 1374-1377, https://doi.org/10.1021/ol5001389.

[111] K. Tsubokura, K.K.H. Vong, A.R. Pradipta, A. Ogura, S. Urano, T. Tahara, S Nozaki, H. Onoe, Y. Nakao, R. Sibgatullina, A. Kurbangalieva, Y. Watanabe, K. Tanaka, In vivo gold complex catalysis within live mice, Angew. Chem. Int. Ed. 56 (2017) 3579-3584, https://doi.org/10.1002/anie.201610273.

[112] A.M. Pérez-López, B. Rubio-Ruiz, V. Sebastián, L. Hamilton, C. Adam, T.L. Bray, S. Irusta, P.M. Brennan, G. Lloyd-Jones, D. Sieger, J. Santamaría, A. UncitiBroceta, Gold-triggered uncaging chemistry in living systems, Angew. Chem. Int. Ed. (2017), https://doi.org/10.1002/anie.201705609.

[113] Z. Liu, A. Habtemariam, A.M. Pizarro, S.A. Fletcher, A. Kisova, O. Vrana, L. Salassa, P.C.A. Bruijnincx, G.J. Clarkson, V. Brabec, P.J. Sadler, Organometallic half-sandwich iridium anticancer complexes, J. Med. Chem. 54 (2011) 30113026, https://doi.org/10.1021/jm2000932.
[114] Z. Liu, A. Habtemariam, A.M. Pizarro, G.J. Clarkson, P.J. Sadler, Organometallic iridium(III) cyclopentadienyl anticancer complexes containing C,N-chelating ligands, Organometallics 30 (2011) 4702-4710, https://doi.org/10.1021/ om2005468.

[115] Z. Liu, I. Romero-Canelõn, B. Qamar, J.M. Hearn, A. Habtemariam, N.P.E. Barry, A.M. Pizarro, G.J. Clarkson, P.J. Sadler, The potent oxidant anticancer activity of organoiridium catalysts, Angew. Chem. Int. Ed. 53 (2014) 3941-3946, https://doi.org/10.1002/anie.201311161.

[116] S. Bose, A.H. Ngo, L.H. Do, Intracellular transfer hydrogenation mediated by unprotected organoiridium catalysts, J. Am. Chem. Soc. (2017), https://doi. org/10.1021/jacs.7b03872.

[117] A.H. Ngo, M. Ibañez, L.H. Do, Catalytic hydrogenation of cytotoxic aldehydes using nicotinamide adenine dinucleotide (NADH) in cell growth media, ACS Catal. 6 (2016) 2637-2641, https://doi.org/10.1021/acscatal.6b00395.

[118] P.K. Sasmal, S. Carregal-Romero, A.A. Han, C.N. Streu, Z. Lin, K. Namikawa, S.L. Elliott, R.W. Köster, W.J. Parak, E. Meggers, Catalytic azide reduction in biological environments, ChemBioChem 13 (2012) 1116-1120, https://doi. org/10.1002/cbic.201100719.

[119] C.E. Valdez, Q.A. Smith, M.R. Nechay, A.N. Alexandrova, Mysteries of metals in metalloenzymes, Acc. Chem. Res. 47 (2014) 3110-3117, https://doi.org/ 10.1021/ar500227u.

[120] D. Coquière, J. Bos, J. Beld, G. Roelfes, Enantioselective artificial metalloenzymes based on a bovine pancreatic polypeptide scaffold, Angew. Chem. Int. Ed. 48 (2009) 5159-5162, https://doi.org/10.1002/ anie.200901134.

[121] J. Bos, F. Fusetti, A.J.M. Driessen, G. Roelfes, Enantioselective artificial metalloenzymes by creation of a novel active site at the protein dimer interface, Angew. Chem. Int. Ed. 51 (2012) 7472-7475, https://doi.org/ 10.1002/anie.201202070.

[122] J. Bos, W.R. Browne, A.J.M. Driessen, G. Roelfes, Supramolecular assembly of artificial metalloenzymes based on the dimeric protein LmrR as promiscuous scaffold, J. Am. Chem. Soc. 137 (2015) 9796-9799, https://doi.org/ 10.1021/jacs.5b05790.

[123] I. Drienovská, A. Rioz-Martínez, A. Draksharapu, G. Roelfes, Novel artificial metalloenzymes by in vivo incorporation of metal-binding unnatural amino acids, Chem. Sci. 6 (2015) 770-776, https://doi.org/10.1039/C4SC01525H.

[124] Z.J. Wang, H. Renata, N.E. Peck, C.C. Farwell, P.S. Coelho, F.H. Arnold, Improved cyclopropanation activity of histidine-ligated cytochrome P450 enables the enantioselective formal synthesis of levomilnacipran, Angew. Chem. Int. Ed. 53 (2014) 6810-6813, https://doi.org/10.1002/anie.201402809.

[125] C.C. Farwell, R.K. Zhang, J.A. McIntosh, T.K. Hyster, F.H. Arnold, Enantioselective enzyme-catalyzed aziridination enabled by active-site evolution of a cytochrome P450, ACS Cent. Sci. 1 (2015) 89-93, https://doi. org/10.1021/acscentsci.5b00056.

[126] K. Zhang, B.M. Shafer, M.D. Demars, H.A. Stern, R. Fasan, Controlled oxidation of remote $\mathrm{sp}^{3} \mathrm{C}-\mathrm{H}$ bonds in artemisinin via P450 catalysts with fine-tuned regio- and stereoselectivity, J. Am. Chem. Soc. 134 (2012) 18695-18704, https://doi.org/10.1021/ja3073462.

[127] R. Singh, J.N. Kolev, P.A. Sutera, R. Fasan, Enzymatic $\mathrm{C}\left(\mathrm{sp}^{3}\right)-\mathrm{H}$ amination: P450-catalyzed conversion of carbonazidates into oxazolidinones, ACS Catal. 5 (2015) 1685-1691, https://doi.org/10.1021/cs5018612.

[128] H.M. Key, P. Dydio, D.S. Clark, J.F. Hartwig, Abiological catalysis by artificial haem proteins containing noble metals in place of iron, Nature 534 (2016), https://doi.org/10.1038/nature17968.

[129] P. Dydio, H.M. Key, A. Nazarenko, J.Y.-E. Rha, V. Seyedkazemi, D.S. Clark, J.F. Hartwig, An artificial metalloenzyme with the kinetics of native enzymes, Science (80-) 354 (2016) 102-106, https://doi.org/10.1126/science.aah4427.

[130] V. Köhler, Y.M. Wilson, M. Dürrenberger, D. Ghislieri, E. Churakova, T. Quinto, L. Knörr, D. Häussinger, F. Hollmann, N.J. Turner, T.R. Ward, Synthetic cascades are enabled by combining biocatalysts with artificial metalloenzymes, Nat. Chem. 5 (2012) 93-99, https://doi.org/10.1038/ nchem.1498.

[131] Y.M. Wilson, M. Dürrenberger, E.S. Nogueira, T.R. Ward, Neutralizing the detrimental effect of glutathione on precious metal catalysts, J. Am. Chem. Soc. 136 (2014) 8928-8932, https://doi.org/10.1021/ja500613n.

[132] Y. Okamoto, V. Köhler, T.R. Ward, An NAD(P)H-dependent artificial transfer hydrogenase for multienzymatic cascades, J. Am. Chem. Soc. 138 (2016) 5781-5784, https://doi.org/10.1021/jacs.6b02470.

[133] A. Chatterjee, H. Mallin, J. Klehr, J. Vallapurackal, A.D. Finke, L. Vera, M. Marsh, T.R. Ward, An enantioselective artificial Suzukiase based on the biotinstreptavidin technology, Chem. Sci. 7 (2016) 673-677, https://doi.org/ 10.1039/C5SC03116H.

[134] M. Jeschek, R. Reuter, T. Heinisch, C. Trindler, J. Klehr, S. Panke, T.R. Ward, Directed evolution of artificial metalloenzymes for in vivo metathesis, Nature 537 (2016) 661-665, https://doi.org/10.1038/nature19114.

[135] V. Gayakhe, Y.S. Sanghvi, I.J.S. Fairlamb, A.R. Kapdi, Catalytic C-H bond functionalisation of purine and pyrimidine nucleosides: a synthetic and mechanistic perspective, Chem. Commun. 51 (2015) 11944-11960, https:// doi.org/10.1039/C5CC03416G.

[136] J. Rodríguez, J. Mosquera, J.R. Couceiro, M.E. Vázquez, J.L. Mascareñas, Ruthenation of non-stacked guanines in DNA G-quadruplex structures: enhancement of c-myc expression, Angew. Chem. Int. Ed. 55 (2016) 1561515618, https://doi.org/10.1002/anie.201607965. 